Article

\title{
Sustainable Distribution Organization Based on the Supply-Demand Coordination in Large Chinese Cities
}

\author{
Sijing Liu ${ }^{1,2, *}$, Jiuping $\mathrm{Xu}^{2}{ }^{(\mathbb{D}}$, Xiaoyuan Shi ${ }^{2}$, Guoqi $\mathrm{Li}^{1,3}$ and Dinglong Liu ${ }^{1}$ \\ 1 National United Engineering Laboratory of Integrated and Intelligent Transportation, School of \\ Transportation \& Logistics, Southwest Jiaotong University, Chengdu 610031, China; \\ guoqi@swjtu.edu.cn (G.L.); darren.laua@gmail.com (D.L.) \\ 2 Business School, Sichuan University, Chengdu 610044, China; xujiuping@scu.edu.cn (J.X.); \\ 2015141083021@stu.scu.edu.cn (X.S.) \\ 3 Institute of Geographic Sciences and Natural Resources Research, Chinese Academy of Sciences, \\ Beijing 100101, China \\ * Correspondence: liusijing@swjtu.edu.cn
}

Received: 7 August 2018; Accepted: 24 August 2018; Published: 27 August 2018

\begin{abstract}
In large Chinese cities, inefficient logistics organization, a rapid increase in freight demand, and the spreading of city logistics space have jointly contributed to the urban problems related to goods movement, such as spatial conflicts, traffic congestion, and air pollution. To address these problems and improve urban sustainability, we proposed a new spatial organization model of supply-demand coordination. We used the data from the Third China Economic Census and online point-of-interest (POI) for China's four direct-controlled municipalities and 13 sub-provincial cities. We found that: (1) the freight supply and demand in China's large cities are both spatially decentralized and clustered. However, there is a significant spatial mismatch between freight supply and demand in most of the studied cities. (2) The 17 studied cities can be divided into three types-highly unbalanced, unbalanced, and balanced-in light of the spatial mismatch between freight supply and demand. (3) The capacities of road surface and logistics nodes spatially differ. The supply capacity of the road systems in Beijing, Shanghai, and Guangzhou can only accommodate $18.4 \%, 35.5 \%$, and $32.2 \%$ of the demand, respectively, while the supply capacity of the logistics nodes is more than twice that of the actual demand in these cities. Based on the findings, this paper proposed a differentiated method of demand management in different areas of the cities. To achieve the goals of low-carbon and sustainable development in logistics distribution, policy makers may consider planning urban freight activities along metro lines and intercity rail lines. Thus, this paper will provide a new perspective for understanding the urban freight distribution and management in large Chinese cities.
\end{abstract}

Keywords: distribution mode; supply and demand; sustainable development; city logistics

\section{Introduction}

Goods in cities are generally delivered in small batches, at multiple frequencies, and within a very limited time. Such distribution activities in cities incur the highest costs while tending to have the lowest efficiency in the organization of logistics chains. In addition, city distribution is largely and continuously impacted by many factors such as city freight management, city production, consumption, and circulation space reconstruction, resulting in traffic congestion, air pollution, and space conflict, which are harmful to the sustainable development of the cities [1,2]. Large cities, in which an increasing number of logistics enterprises and facilities concentrate, generally serve 
as the gateway and hub and become the core of distribution organization and management [3-5]. In metropolis cities such as London and Paris, the volumes of goods generated by city distribution account for a quarter of those cities' traffic volumes, about $20 \%$ to $30 \%$ of vehicle kilometers [1]. To reduce the impact of logistics activities on the environment, logistics facilities gradually sprawl from downtown to the suburbs. In Paris, Los Angeles, and Toronto, the average distance of these facilities from the urban center increased by nine $\mathrm{km}$, while the same tendency is also apparent in both Tokyo and Atlanta. City logistics sprawling has intensified the separation between logistics activity space and service objects, and, as a result, freight handling activities increase significantly. In the metropoles of developing countries such as India and Brazil, transportation planning focuses more on passenger transportation and intercity freight, and less attention is paid to logistics demands within the cities. The insufficient planning of city logistics space makes it difficult to deal with the "last mile" distribution [6-9].

With the promotion of information technology and intelligent manufacturing, smart logistics and smart city concepts have emerged, and new equipment such as unmanned vehicles, fully electric vehicles, and locker boxes are widely used $[10,11]$. At the same time, new organizations and business models, such as joint distribution, matching platforms between vehicles and cargos, and freight forwarder, keep on surfacing and effectively reduce the waiting time and labor input of city distribution. Through the implementation of the innovative logistics system, $\mathrm{CO}_{2}$ emissions in several cities in Europe have decreased by $84 \%$, and the environmental pollution is mitigated, but the long-term effect of city distribution management still needs to be tested [12-15]. Research on the European Union (EU) shows that city logistics management is so difficult that in $60 \%$ of EU cities, $55 \%$ of vehicle emissions are caused by goods distribution, and $40 \%$ of cargo are shipped to the downtown areas for reasons such as its larger population and commercial density; meanwhile, differences between city logistics service requirements and spatial separation have intensified the imbalance between freight supply and demand $[10,16]$.

There are 30 cities with more than eight million permanent residents in China in 2017. The increase in customers' demand for quality and the timeliness of logistics services has accelerated the changes in the number, types, and functions of service providers, and to a certain extent prompted the disorderly spread of logistics activities. In addition, China, entering a critical period of urbanization, is inevitably facing the huge challenge of sustainable development $[17,18]$. Several large cities in China have issued the development plans for the logistics industry since "The 10th Five-Year Plan", but the focus in those plans was on large-scale logistics nodes such as logistics parks and logistics centers without adequate consideration given to the layout of city distribution facilities and terminals for end consumers and supermarkets, such as distribution centers and warehouses $[2,19]$. Therefore, distribution problems have become a hot spot of social concern and pressure point in the logistics field [20-23]. The rapid expansion of the e-commerce consumer market has further fragmented and personalized distribution demands, thanks to the e-platforms such as Alibaba and JD. Take Chinese express delivery industry as example; in 2016, the industry used approximately 3.2 billion woven bags, 6.8 billion plastic bags, and 8.6 billion packaging boxes [24-26]. However, it is difficult to accurately present the characteristics of city distribution supply and demand, and reveal the diversity of logistics distribution space between different cities, as the logistics data available are not systematic and comprehensive enough in China; population mobility and city space expansion are fast $[18,27]$.

In view of the above, (1) this paper has integrated the data of government's economic census and POI on the internet to better present the status quo of the logistics industry in China. After considering the influence of various factors and complex internal relations between supply and demand, analogy methods are used to estimate the city distribution demand and supply; (2) this paper has revealed the spatial pattern of supply and demand space in differentiated areas of different cities, which can help illuminate the influence of spatial structure and its differences on the design of city distribution management mode [16]; (3) the authors took into consideration the efficient rail transportation system, the relatively concentrated distribution demands in large Chinese cities, and proposed sustainable 
distribution strategies from the perspective of spatial differentiation such as city distribution based on a metro rail network, the layout of joint distribution centers and dedicated distribution lanes, and the application of electric trucks and green packaging, which can reduce distribution costs, improve logistics land-use efficiency, and reduce air pollution.

\section{Literature Review}

To build a link between the existing literature and this research work, we developed a structured literature browsing method that mainly consists of four key steps [28,29]:

(1) Search for articles in databases and other sources, such as Scopus, CJFD (China Academic Journals Full-text Database), Web of Science, and so on.

(2) Reduce the number of articles by reading the abstract and identifying the main topic and keywords.

(3) Retrieve additional articles by tracking the research cited in some studies and supplementing the key Chinese articles.

(4) Divide the main categories, discuss the key scientific results, and identify the scientific gaps, and bottlenecks.

Firstly, we referred to the Scopus database, because it contains the main journals from this research work. The following list of keywords (and their combinations) were used to search for the studies: city or urban logistics (distribution, delivery) and sustainability; supply and demand; demand forecasting; logistics sprawl. In order to reflect the latest research trends, we decided to include English language journal articles from 2008 to 2018 only. Initially, 364 articles were identified. The search was conducted in August 2018. Secondly, the entire set of selected articles was reduced to 25 articles by restricting the topic area and reading the abstracts and keywords.

As demonstrated in Figure 1, the number of the selected articles has increased in the last years, which means that this research field is getting more and more attention.

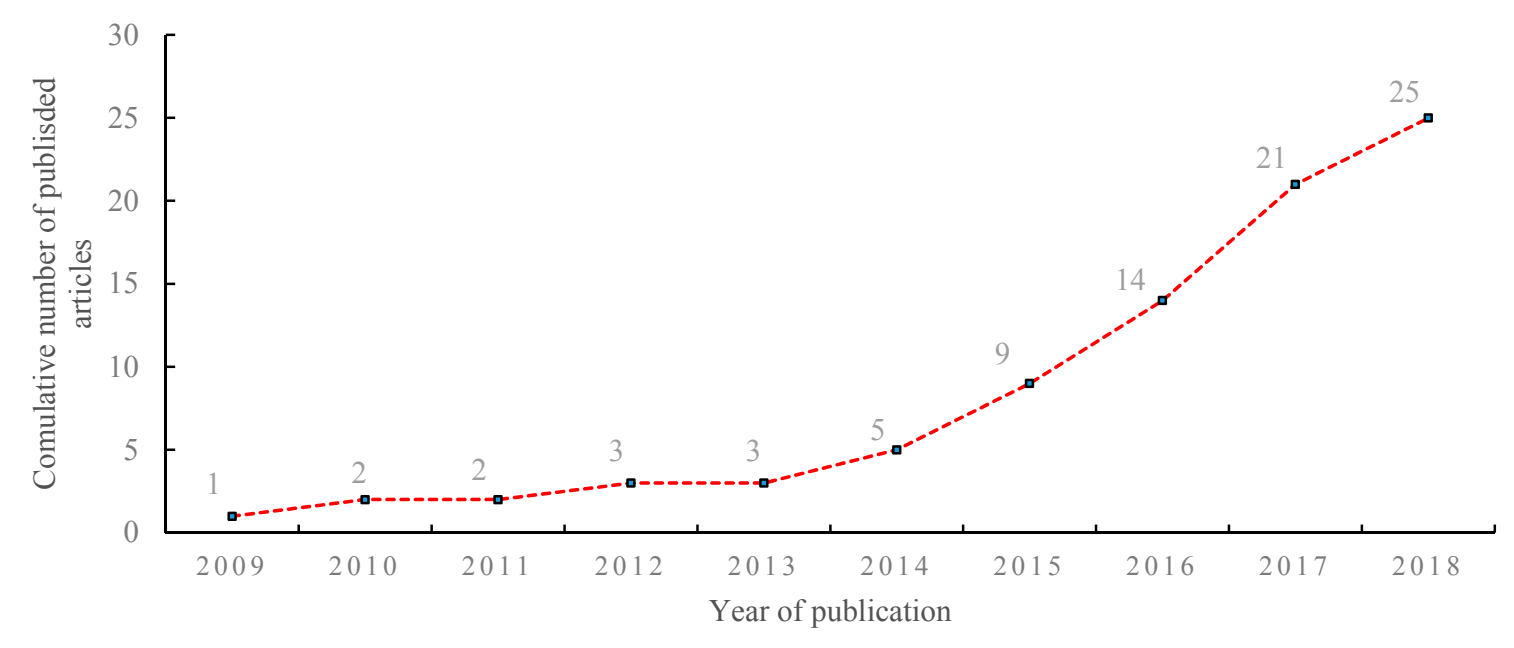

Figure 1. Classification of articles by year of publication.

The selected article uses a lot of similar keywords, and some keywords are rarely used. The most frequently used keywords (greater than or equal to four times) are depicted in Figure 2. Freight activities and logistics are closely linked. To mitigate the environmental impact of urban logistics and freight activities, diversified distribution facilities and strategies are widely mentioned, such as for example: fully electric vehicles, cargo tricycles, off-hour delivery, cycle transport, non-motorized transport, mobile depot, and joint distribution center [30-33]. The question of how to effectively control the increasing demand for urban distribution has become the core of urban 
distribution management. A series of models and algorithms for demand analysis and prediction has become one of the research hotspots $[34,35]$.

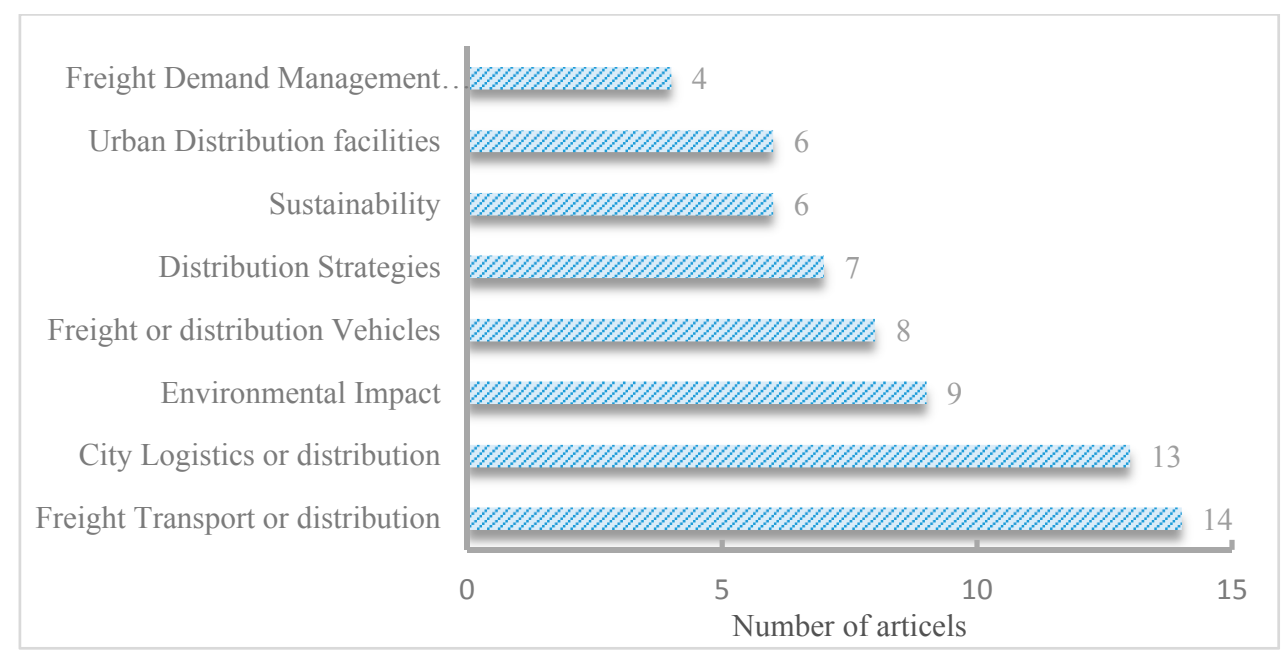

Figure 2. Classification of articles considering the used keywords.

By analyzing the most cited articles, we can further understand the direction of research in this field (see Figure 3). In the implementation of logistics policy, it is necessary to consider differentiated distribution patterns, characteristics of freight demand, and socio-economic characteristics [36]. The sustainable development of urban distribution faces enormous challenges, featuring restrictive measures of local authorities, rapid increases in demand, and lower vehicle utilization efficiency as key restrictions [35,37]. The effective coordination of the interests of multiple stakeholders and anticipation of new technologies are very critical approaches [38].

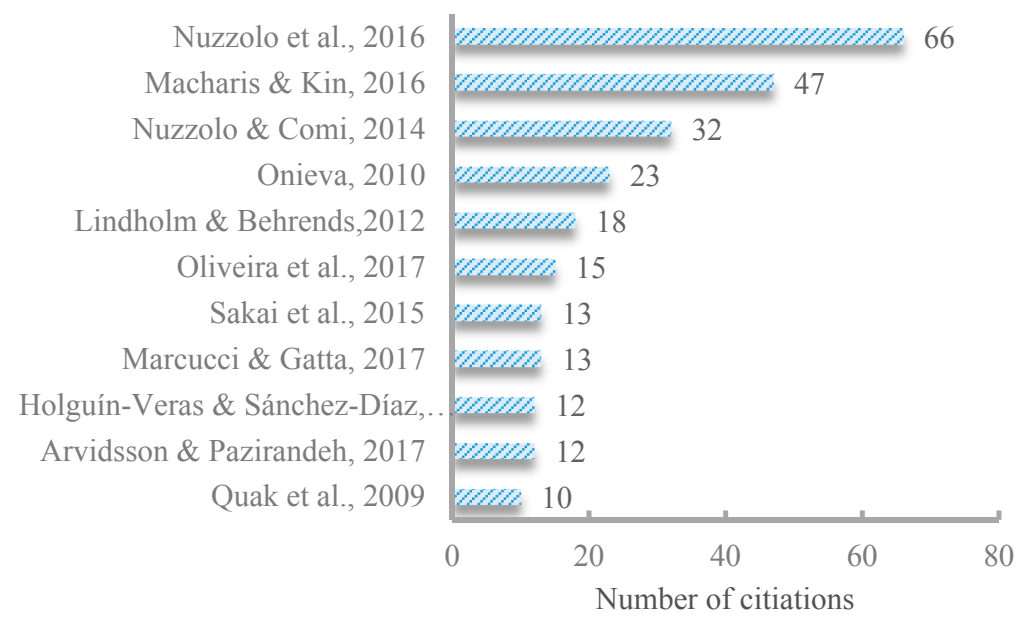

Figure 3. The most cited articles based on a search in the Scopus database.

In order to make up for the shortcomings of the Scopus database, and fully consider China's national conditions, we have added more than 20 additional articles by tracking the research cited in the selected 25 articles in the first stage. At the same time, more than 10 Chinese papers and books are selected in CJFD. According to the research theme, the above articles are divided into the following three categories for detailed discussion. 


\subsection{Characteristics and Influencing Factors of Distribution Demand and Supply}

The city distribution system is defined as the interaction between two components: supply and demand [39-41]. As a derivative demand, city distribution is affected by the population and growth rate, economic development level, and supply chain system [11,12,42]. Its specific manifestations including packs of consumer goods, city construction materials, waste, postal parcels, and other related items according to customer requirements $[1,18]$. New business model and distribution strategies help match supply and demand for distribution services [43,44]. With the gradual diversification of city space, some scholars have proposed the concept of freight landscape, using spatial distribution, freight demand density, and freight flow indicators to explain the spatial distribution characteristics of freight activities and intensity in metropolises [16]. The supply of city distribution is reflected by warehousing and logistics facilities, vehicles, operational efficiency, etc. [41,45]. It can also be described by the number of freight trucks, the per capita storage area, the distance from the distribution center to the central business districts, and the service level of roads $[5,46]$. Although the demand and supply of city distribution are decentralized, most of the demands arise from downtown areas. The investment intensity, population density, and freight management strategy of city transportation logistics land have aggravated the contradiction between supply and demand, highlighting the important role of government in city distribution management [47]. The accurate understanding of urban distribution supply and demand characteristics is the key to the sustainable development of distribution $[36,48]$.

\subsection{City Freight Demand Analysis and Forecasting}

The demand analysis of city freight activities is influenced by multiple participants such as consumers, producers, wholesalers, and retailers. Accurate prediction is very difficult [49]. The traditional freight demand models seem to be more suitable for regional and national planning than for the city one. Some scholars have proposed forecasting demand from different commodity types and final consumer demand [50,51]. The microsimulation models representing explicit tours and individual shipments are difficult to apply to the analysis of the total demand of distribution [29].

Generally speaking, four major types of methods are used to analyze and forecast freight demands. The first type, prediction methods based on traditional statistics, mainly include the Markov chain, elastic coefficient method, input-output model, freight intensity method, clustering method, grey theory model, regression analysis method, etc. [52-54]. The disadvantage of these methods is that they require a long period of historical data and are based on linear regression. The second type of method, artificial intelligence-based prediction methods, covers artificial neural networks, expert system inference rules, and so on. Although this type of method improves the accuracy of prediction to some extent, it is difficult to ensure the accuracy and determine the value of parameters [55]. The third type of method consists of prediction methods based on the four-phase method [40]. Some scholars present a general modeling framework to estimate the quantity, delivery, and vehicle units' OD (origin-destination) matrices [34]. Some scholars divide data into the three categories of variability, reliability, and source. They are static, dynamic, deterministic, probabilistic (random), ambiguous, public, and private [56]. Among this type of method, the data acquisition methods include enterprise surveys, vehicle observation surveys, parking surveys, driver surveys, commodity flow surveys, GPS (global positioning system) surveys, vehicle traffic statistics surveys, etc. The fourth type of method is prediction methods involving special correlation. Some scholars use the spatial interaction gravity model to predict the dynamic logistics generation in downtown areas [57]. When dealing with the status quo of the logistics industry in China, scholars have to face the lack of basic data on city distribution in China and the significant change in distribution demand, and have to take into their account many influencing factors. In this regard, the first two methods are not effective. Demand analysis and forecasting based on OD and spatial analysis are highly accurate, but require huge volumes of survey data [35]. 


\subsection{City Distribution Spatial Patterns and Differences}

The spatial pattern is manifested in three aspects: space sprawling, spatial concentration, and recentralization. (1) Space sprawling refers to the process of expansion and decentralization for warehousing and distribution activities from city centers to suburbs. For example, cities such as Atlanta, Los Angeles, Chicago, Tokyo, and Beijing have followed the trends of warehousing activities expansion and related W\&D (warehouse and distribution) decentralization $[6,58,59]$. (2) Spatial sprawling is also accompanied by the centralization of logistics activities. For example, Cidell surveyed 47 cities in 50 United States (US) city agglomerations from 1986 to 2005, and revealed the suburbanization and centralization trends of warehousing and logistics-related activities from the county scale [60]. The MIT (Massachusetts Institute of Technology) Transportation and Logistics Research Center has paid attention to logistics companies clustering in geospatial space for a long time. Their related researches focused on the formation of logistics industry clusters in Zaragoza, Rotterdam, Memphis, Louisville, and Napoli, as well as the spatial layout characteristics of logistics clusters formed by US logistics establishments [61,62]. As a core facility for logistics activities, some researches have shown that storage facilities are closer to the edge of city commercial centers, such as the empirical studies in Ahmedabad, India, and Beijing, China. Limited by available land, storage facilities are still dispersed to suburbs $[7,18,20]$. (3) The suburbanization of logistics activities has led to a reduced ability in rapid distribution, and some logistics companies have chosen to recentralize their locations. Some scholars have conducted empirical research on the metropolitan area of Paris [63]. In general, the differentiation trend in the distribution pattern of different cities has been quite significant. However, the existing research has focused on supply facilities such as warehousing and distribution, and paid little attention to the difference between supply and demand, which is not conducive to the formulation of distribution management strategies.

\section{Data and Methods}

\subsection{Research Objects, Data Sources, and Processing}

The collection of data on distribution in large cities is the basis for the recognition of the spatial distribution and the interaction of distribution supply and demand. Most of the data from the existing studies in the US is acquired through the statistics of transport, courier, post, distribution, handling, and 27 other sectors in the North American Industrial Classification System [62,64]. At present, China has not yet classified the logistics industry in national economic industries or industrial statistics, and most researchers currently use the statistical data on transportation, warehousing, and postal services, or questionnaires, business registration information, and the yellow pages to obtain logistics data [24]. POI is the core data of location-based services on the map, including the names, categories, and coordinates of all of the merchants, government agencies, streets, etc. In recent years, online map service platforms represented by Baidu, Tencent, and Autonavi Navigation have stored a large number of POIs of corporate and node facilities. Such POI data has been widely used in spatial analysis in the fields of retail, residential, and logistics, etc., and has proven to be very reliable $[18,65,66]$. In this study, a web crawler tool was built and programmed to call the API (application programming interface) platform and collect POIs (see Figure 4). 


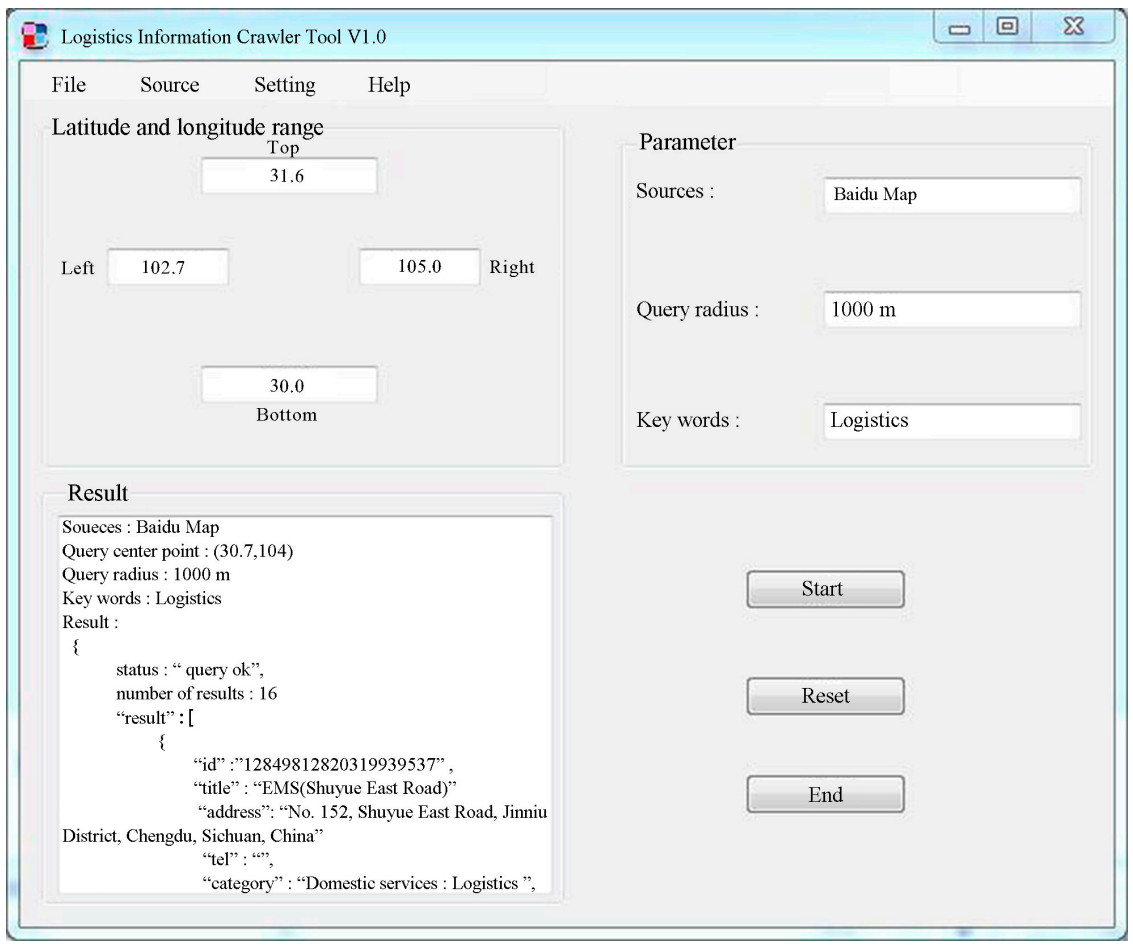

Figure 4. The collection process of point-of-interest (POI) by the web crawler tool.

First, the authors determined the keywords and selected "logistics", "shopping", and "real estate community" in the manuscript. Second, we use the "search nearby" tool to obtain the primary attributes, including the name, latitude, and longitude, address, and contact number via the Baidu Map API, within a search radius of $1000 \mathrm{~m}$. The literature has been added to disclose more technical details $[67,68]$. In this way, logistics data can be acquired more efficiently, and the problem of heterogeneity of data can be solved $[27,66]$. China's directly controlled municipalities and sub-provincial cities generally have the problems of high population density, strong distribution demand, and serious traffic congestion. In consideration of the availability of data, the authors selected 17 Chinese cities as the research objects, and collected, from the Baidu map API platform, POIs as well as China's third economic census data on wholesale and retail trade, transportation, warehousing and postal services, and real estate development and management enterprise corporate units (see Table 1). These two types of data acquired both online and offline are the combination of macro-statistical and micro-facility data, and they are considered to be the main factors affecting city distribution demand and supply $[26,55,64]$. Due to the different acquisition methods and sample objects, the data results of the two are quite different. Furthermore, the authors also collected data on major logistics nodes, industrial parks, and wholesale markets in Beijing and Chengdu to better demonstrate the distribution of logistics demand in typical cities [18]. 
Table 1. Data of POI and the Third China Economic Census for logistics, businesses, and households.

\begin{tabular}{ccccccc}
\hline \multirow{2}{*}{ City } & \multicolumn{2}{c}{ Logistics/Unit: pcs } & \multicolumn{2}{c}{ Business/Unit: pcs } & \multicolumn{2}{c}{ Residential District/Unit: pcs } \\
\cline { 2 - 6 } & Method 1 & Method 2 & Method 1 & Method 2 & Method 1 & Method 2 \\
\hline Beijing & 3450 & 14,290 & 3582 & 190,704 & 11,113 & 3426 \\
Shanghai & 7780 & 15,003 & 3825 & 145,668 & 20,534 & 3766 \\
Tianjin & 1709 & 10,247 & 1311 & 66,133 & 4057 & 1491 \\
Chongqing & 2212 & 4890 & 2454 & 80,577 & 1223 & 3279 \\
Guangzhou & 3564 & 5766 & 3058 & 65,154 & 1156 & 1373 \\
Shenzhen & 3668 & 9149 & 2802 & 84,245 & 5250 & 787 \\
Shenyang & 1642 & 2784 & 1178 & 35,801 & 1311 & 1413 \\
Dalian & 1028 & 3926 & 1066 & 32,284 & 2389 & 1615 \\
Wuhan & 1498 & 3325 & 1599 & 40,849 & 1828 & 1891 \\
Chengdu & 3089 & 2661 & 2787 & 22,346 & 5202 & 1954 \\
Xi'an & 1111 & 1404 & 1466 & 24,205 & 2242 & 1626 \\
Jinan & 937 & 1373 & 861 & 32,093 & 1002 & 754 \\
Qingdao & 1699 & 5600 & 1219 & 52,523 & 2238 & 1302 \\
Hangzhou & 1845 & 3660 & 2053 & 68,329 & 2522 & 1723 \\
Ningbo & 1680 & 3750 & 1044 & 41,753 & 696 & 999 \\
Harbin & 863 & 1542 & 789 & 17,803 & 391 & 1035 \\
Xiamen & 1398 & 2523 & 890 & 25,761 & 314 & 650 \\
\hline
\end{tabular}

Source: Data from Baidu Map (method 1) in October 2014 and China Economic Census Yearbook 2013 (method 2).

\subsection{Research Methods}

\subsubsection{City Distribution Demand Estimation Method}

Existing studies mostly use the volume of freight traffic or freight turnover to replace logistics demand [6,58]. The logistics demand, including transportation, warehousing, distribution, and other operations, is difficult to estimate $[17,42]$. Distribution demand in cities are generally raised by city residents [59]. It has not been included in the statistical index system, and lacks an effective estimation method [69,70]. Currently, the distribution demands of large cities in China are generated in both online and offline shopping, and the demand for online shopping is directly related to the scale of e-commerce in the city, especially the courier parcel volume and the total volume of postal services [17]. Offline shopping is directly related to the scale of the wholesale and retail industry in the city, and the total retail sales of consumer goods as well. Both demands are related to the per capita disposable income of city residents and the influence of the city resident population [2,71]. A small number of cities represented by Guangzhou have carried out surveys on city distribution, which provides an important benchmark for estimating the distribution demand data of other large cities [72]; the analogy calculation method of the city distribution demand is as follows:

$$
D_{i}(x)=\left(\alpha_{i} \times x^{\prime} \times\left(\frac{k_{i}}{k} \times \frac{\rho_{i}}{\rho}\right)+\left(1-\alpha_{i}\right) \times x^{\prime \prime} \times\left(\frac{m_{i}}{m} \times \frac{n_{i}}{n}\right)\right) \times p_{i} \times \frac{\lambda_{i}}{\lambda}
$$

where $D_{i}(x)$ represents the distribution demand amount of city $i$, which consists of online and offline markets. The city resident population and per capita disposable income of city residents are the major factors $[2,11,12]$. The explanation and data sources of the indexes in Formula (1) can be shown in Table 2. 
Table 2. Explanation and data sources of the indexes.

\begin{tabular}{|c|c|c|}
\hline Index & Symbol & The Data Source or Calculation Method \\
\hline The proportional proportion of online shopping & $\alpha_{i}$ & $\alpha_{i}=\frac{e_{i}}{m_{i}}$ \\
\hline $\begin{array}{l}\text { Annual online shopping distribution amount } \\
\text { per capita in Guangzhou } / \mathrm{kg}\end{array}$ & $x^{\prime}=360$ & Source: [72] \\
\hline $\begin{array}{l}\text { Annual offline shopping distribution amount } \\
\text { per capita in Guangzhou } / \mathrm{kg}\end{array}$ & $x^{\prime \prime}=3240$ & \\
\hline $\begin{array}{l}\text { Online shopping transaction amount of city } \\
\text { i/hundred million yuan }\end{array}$ & $e_{i}$ & \multirow{2}{*}{ China Post Industry Statistics Report } \\
\hline $\begin{array}{l}\text { Courier business amount of city } i \text { or } \\
\text { Guangzhou/ten thousand pieces }\end{array}$ & $k_{i}, k$ & \\
\hline $\begin{array}{l}\text { Retail sales of social consumer goods of city } i \text { or } \\
\text { Guangzhou/hundred million yuan }\end{array}$ & $m_{i}, m$ & \multirow{4}{*}{ China Statistical Yearbook } \\
\hline $\begin{array}{l}\text { Number of legal person units in the wholesale } \\
\text { and retail industry }\end{array}$ & $n_{i}, n$ & \\
\hline $\begin{array}{l}\text { The number of city resident } \\
\text { population/ten thousand }\end{array}$ & $p_{i}$ & \\
\hline $\begin{array}{l}\text { Per capita disposable income of city residents } \\
\text { in city } i \text { or Guangzhou/yuan }\end{array}$ & $\lambda_{i}, \lambda$ & \\
\hline City Online Shopping Index & $\rho_{i}, \rho$ & $\begin{array}{l}\text { aEDI (Alibaba E-commerce } \\
\text { Development Index) }\end{array}$ \\
\hline
\end{tabular}

The rationality of the formula is guaranteed in several aspects. (1) First, it considers that China's city distribution is composed of two parts, online and offline, and the ratio of the two can be directly calculated through statistical data. (2) The influencing factors of online and offline distribution are determined on the basis of actual survey work and the related literatures. (3) After considering the availability of data, Guangzhou's distribution volume of 32.03 million tons in 2011 was used as benchmark data to verify the validity of Formula (1) [72]; the main verification process is as follows:

(1) The proportional amount of online shopping is calculated, and $\alpha_{i}=0.05$. Therefore, it can be concluded that in 2011, the annual distribution of the city's annual online shopping distribution amount was 1.6 million tons, and the annual offline shopping distribution amount per capita was approximately $130 \mathrm{~kg}$, while the annual total distribution amount per capita was approximately $2470 \mathrm{~kg}$.

(2) According to the scale and growth rate of China's online shopping market in 2011-2013 [73], the annual growth rate of $50 \%$ is determined, and $\alpha_{i}=0.1$. Furthermore, it can be calculated that in 2013, the annual online shopping distribution amount per capita was $360 \mathrm{~kg}$, and the annual offline shopping distribution amount per capita was approximately $3240 \mathrm{~kg}$. In 2013, the total distribution volume in Guangzhou was 46.54 million tons, with an average annual growth rate of $21 \%$.

(3) After comparing the above calculation results with the 44.49 million tons of total distribution volume in the results of the distribution survey performed by Guangzhou City, a difference of only 2.05 million tons occurs, and the error rate is $-4.6 \%$, which fully demonstrated the reliability and validity of Formula (1).

Considering that all of the indicators in Formula (1) can be collected through statistical yearbooks and aEDI, the distribution demand in different cities can be estimated. 


\subsubsection{City Distribution Supply Capacity Estimation Method}

The balance between logistics supply and demand is the main goal of the logistics system operation $[39,40]$. The existing research studies have focused on the forecast and analysis of logistics demand, and the capacity and length indicators of the transportation infrastructure are mostly used in the evaluation of the logistics supply level [53,54]. The distribution system capacity is the combined effects of city road capacity and facility capacity. City road resources represent road capacity. The authors take into their account the current city truck management in China, the number of passenger cars owned in the city per person, and the impact of the number of trucks with city pass [2]. The node capacity is mainly characterized by city warehousing and logistics land resources. The layout of the large logistics parks and logistics centers within the city, as well as the distance to areas with concentration of distribution demands, all exert a strong influence on how the node capacity is efficiently converted into road capacity [18]. Based on the calculation of the capacity of city roads and the method of calculating the scale of storage and logistics land use [74,75], the estimation formula of the city distribution supply capacity is as follows:

$$
S_{i}(y)=\frac{s_{i}}{3.5 l_{i}} \times y_{i} \times \gamma_{i}
$$

where $S_{i}(y)$ represents the road capacity of city $i$, which is determined by the road area and length, the traffic flow, and the number of commercial trucks and personal cars.

$$
S_{i}^{\prime}\left(y^{\prime}\right)=s_{i}^{\prime} \times y_{i}^{\prime} \times \sigma_{i}
$$

where $S_{i}^{\prime}\left(y^{\prime}\right)$ represents the node capacity of city $i$, which is determined by the logistics and storage area, the logistics processing capacity, and total distribution demand.

These calculation methods have been widely adopted in the planning and design department of China for city logistics nodes and channel layouts. The node capacity and road capacity can ultimately be converted into the number of box vans in cities to evaluate the matching degree between city supply and demand. The explanation and data sources of the indexes in Formulas (2) and (3) can be shown in Table 3. Since all of the indicators in Formulas (2) and (3) can be collected through statistical yearbooks and industry standards, the distribution supply capacity in different cities can be estimated.

\begin{tabular}{|c|c|c|}
\hline Index & Symbol & The Data Source or Calculation Method \\
\hline $\begin{array}{l}\text { Road area in city } i \\
\text { Road length in city } i\end{array}$ & $\begin{array}{l}s_{i} \\
l_{i}\end{array}$ & China City Statistical Yearbook \\
\hline Average daily traffic capacity of one lane in city $i$ & $y_{i}$ & Source: [75] \\
\hline Truck road resources occupation ratio in city $i$ & $\gamma_{i}$ & $\gamma=\left(\frac{q_{i}}{q_{i}+q_{i}^{\prime}}\right) \times \xi$ \\
\hline $\begin{array}{l}\text { The number of standard truck } \\
\text { The number of private-owned cars }\end{array}$ & $\begin{array}{l}q_{i} \\
q_{i}^{\prime}\end{array}$ & China City Statistical Yearbook \\
\hline Reduction coefficient & $\xi$ & $\begin{array}{l}\text { The value is } 0.2-1 \text { according to the freight } \\
\text { traffic management method }\end{array}$ \\
\hline Logistics and storage area in city $i$ & $s_{i}^{\prime}$ & China City Statistical Yearbook \\
\hline $\begin{array}{c}\text { Annual logistics processing capacity per mu (Ten } \\
\text { thousand tons } / \mathrm{mu} \text { ) }\end{array}$ & $y_{i}^{\prime}$ & Source: $[40,74]$ \\
\hline The proportion of city distribution in freight traffic & $\sigma_{i}$ & $\sigma_{i}=\frac{D_{i}(x)}{Q_{i}}$ \\
\hline Total freight traffic in city $i$ & $Q_{i}$ & China City Statistical Yearbook \\
\hline
\end{tabular}

Table 3. Explanation and data sources of the indexes.

\section{Spatial Pattern of Distribution Supply and Demand in 17 Typical Cities}

Based on the data sources and research methods in Part 2, the POI and the third economic census data were tested for correlation. The distribution demand and supply estimation methods were 
used to reveal the distribution characteristics of supply and demand in typical cities. These results can lay the foundation for coordinated supply and demand distribution management models for sustainable development.

\subsection{Distribution Spatial Patterns and Characteristics in Typical Cities}

To verify the validity of online and offline data, the correlation analysis between the POI data and the third economic census data in Table 1 is shown in Figure 5.

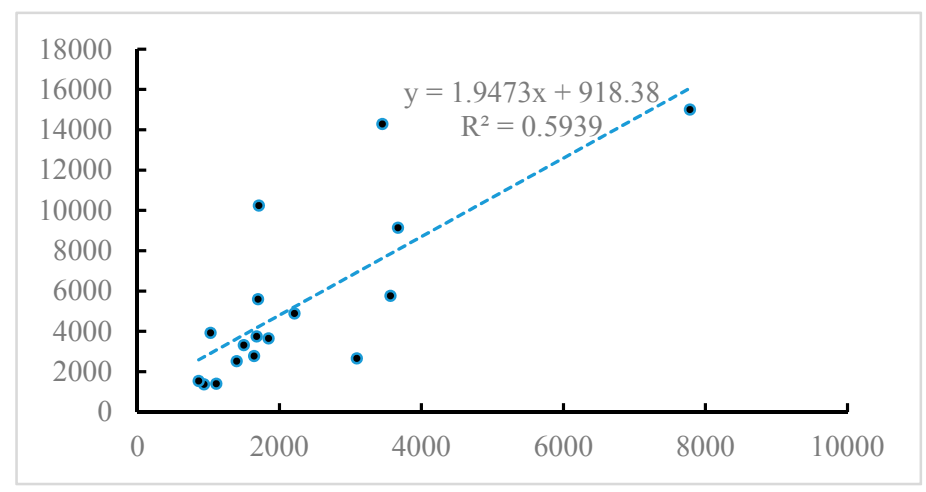

a. The correlation of logistics data.

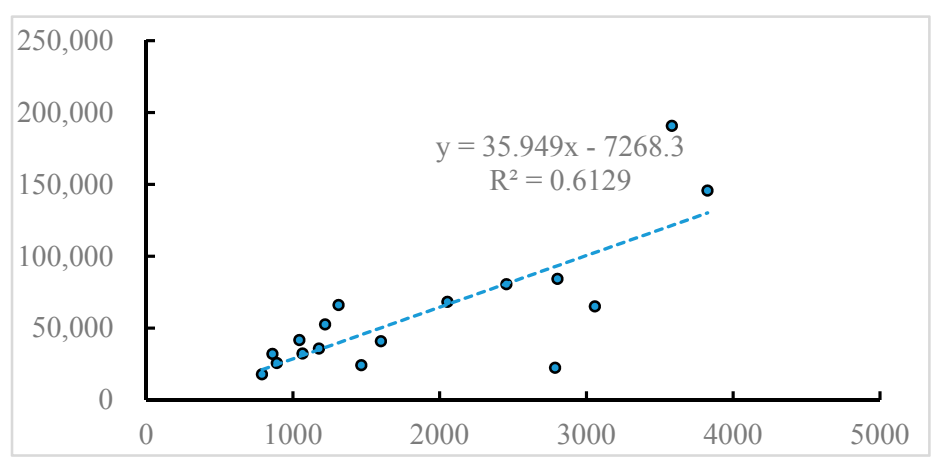

b. The correlation of business data.

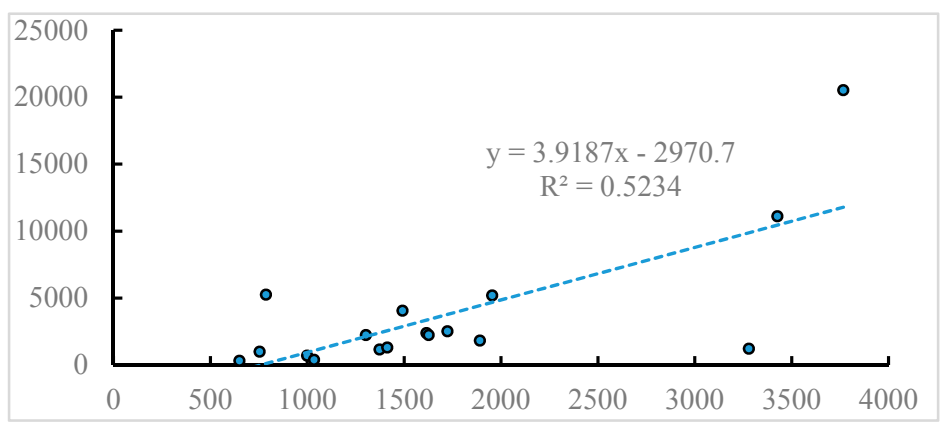

c. The correlation of residential district data.

Figure 5. Correlation analysis between the POI data and the third economic census data.

As seen from Figure 5, the correlation of retail and wholesale businesses is relatively high, and the online map service platform focuses on providing information on food, entertainment, shopping, etc. However, the correlation between logistics data and residential district data is slightly lower, since the relevant data collected from the transportation, warehousing, and postal industries contains a large amount of passenger transport enterprise data, and the corresponding POI data are not collected. As is known to all, the scales of the real estate development companies differ substantially, not to 
mention the sizes and magnitudes of their residential projects. To solve the current problem of data missing in China's logistics industry, the use of POI data for analysis of distribution spatial patterns has strong practical significance, and the effectiveness has also been fully tested $[18,66]$. Therefore, the authors extract POI data, such as 4476 pieces of distribution-related data (accounting for $11.43 \%$ of total logistics data), 31,984 pieces of shopping data, and 63,468 pieces of residence data. Simultaneously, we collected the logistics, transportation, and business planning text, in an attempt to uncover the spatial distribution pattern of the supply and demand of the distribution.

First of all, Beijing and Chengdu, which have regular logistics development planning and complete logistics statistics and survey data, are selected as typical cases, and their spatial patterns of supply and demand are further analyzed (see Figures 6 and 7).

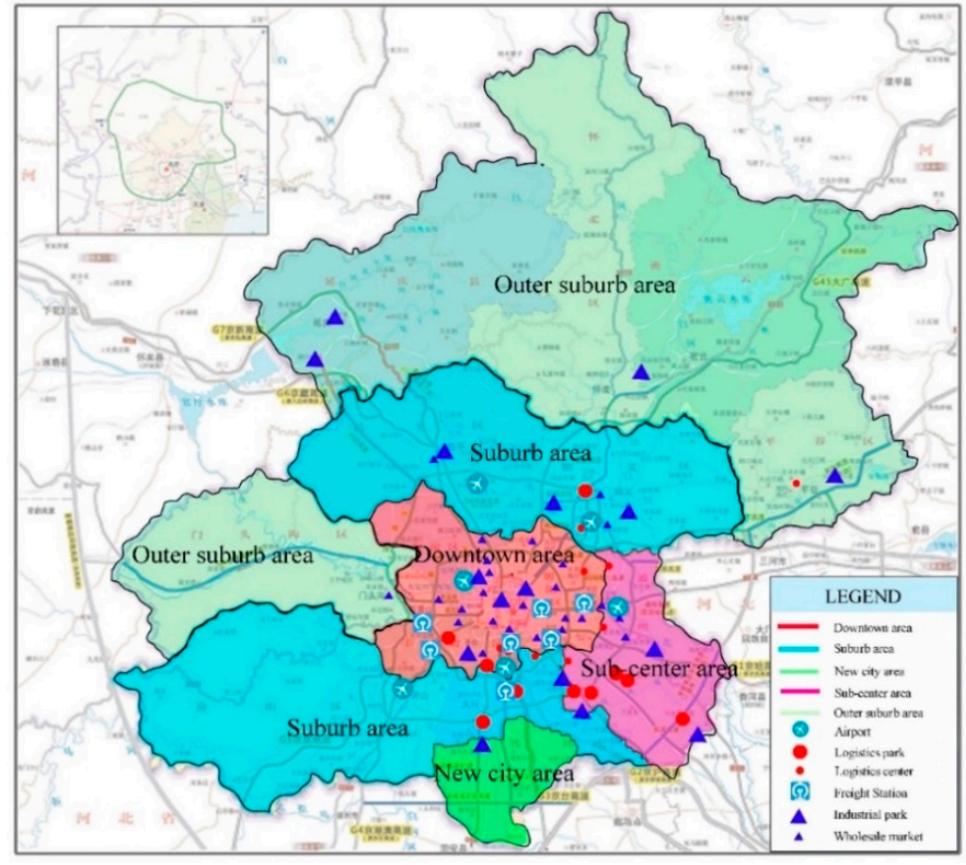

Figure 6. The spatial pattern of supply and demand in Beijing, China.

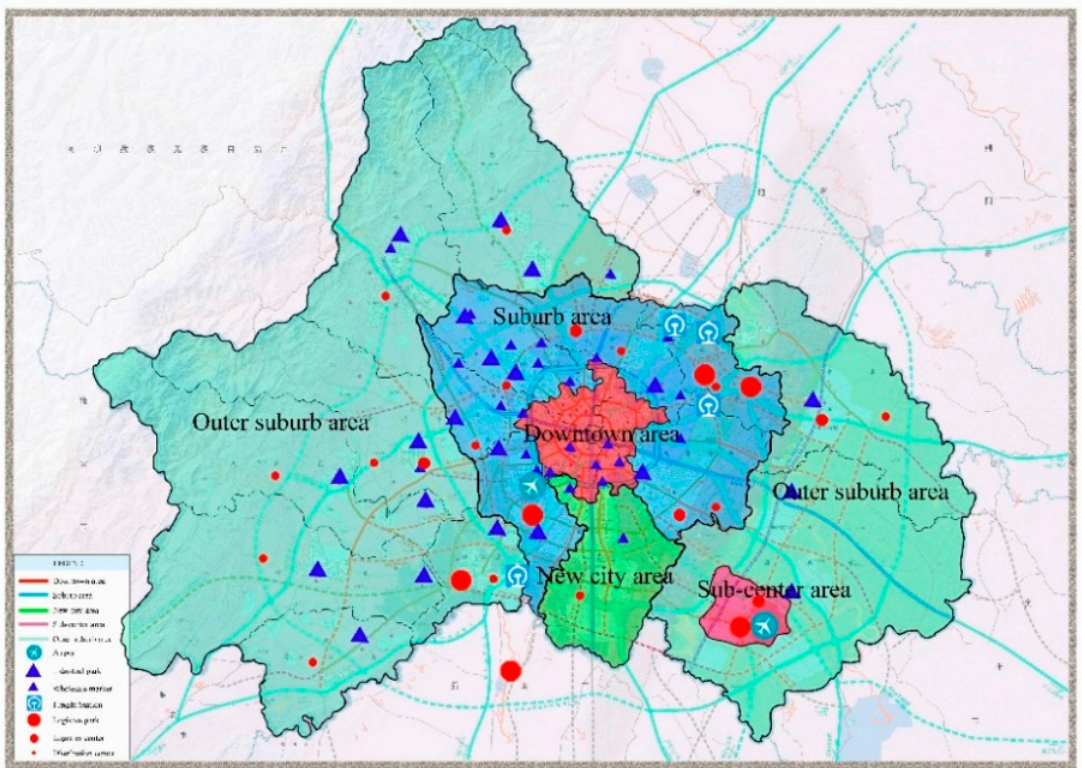

Figure 7. The spatial pattern of supply and demand in Chengdu, China. 
In Figures 6 and 7, the authors divide the city into its downtown area, suburb area, outer suburb area, new city area, and subcenter area. The main distribution supply points are the logistics parks, logistics centers, and distribution centers, and the main distribution demand points are the industrial parks and wholesale markets $[18,76]$. Since the spatial structures of these typical cities and existing research results are similar, the main features of supply and demand are as follows:

(1) Suburbanization and multicenters: Most of the 17 sampled cities have established new city areas, subcenters, or satellite cities. Some of the new city areas have become national-level new areas, e.g., Binhai New Area, Liangjiang New Area, Xixian New Area, Tianfu New Area, etc. [77]. In the process of function adjustment and the spatial expansion in the cities, the relocation of logistics distribution facilities is inevitable. For instance, in the coordinated development of Beijing-Tianjin-Hebei, the relocation of the Beijing logistics function into Hebei is a major work. Statistically, in non-port cities, the logistics distribution facilities have been moved nearly $15-30 \mathrm{~km}$ away from the city center in nearly 10 years. The suburbanization of distribution facilities exceeds that of residence in both scale and speed, and such a trend has manifested in many large cities in European countries, the United States, and Japan [78]. In certain port cities, such as Shanghai, Tianjin, Chongqing, and Shenzhen, the logistics distribution facilities are $40-60 \mathrm{~km}$ away from the city centers, because most of the ports are located away from the city center [2].

(2) Interdependence and differentiation: The spatial interdependence is reflected in that city distribution facilities are located close to a large city's residential areas and large commercial complexes, and they coexist in a region. The spatial variation is reflected in that the downtown area is still the business center, and its population density is higher than that of the suburban and new city areas. Thanks to the adjustment of city functions and spatial distribution, the distance between distribution facilities and the downtown areas is farther and farther, and the distribution demand of the downtown areas cannot be met in a timely and effective manner, resulting in obvious spatial variation. For instance, the distance between the distribution centers and allocating centers built by Beijing enterprises is $21.957 \mathrm{~km}$, outside the fifth ring road of Beijing, while the main demands of city distribution are concentrated on the areas circled by the fourth ring road. With the increase in distribution demands from e-commerce activities, the government has begun to consider the centralization of the distribution facilities [18].

Based on a summary of typical cases and general spatial characteristics, it is obvious that the expansion of space in China's big cities is accelerating, and the suburbanization trend of logistics space is unavoidable [2]. China's larger cities have common problems such as excessive population growth, commercial concentration, large distribution demand, road congestion, and similar road networks; so, the authors can summarize the general characteristics of the distribution demand and supply space pattern of central cities in China as follows based on Figures 6 and 7 (see Figure 8). 


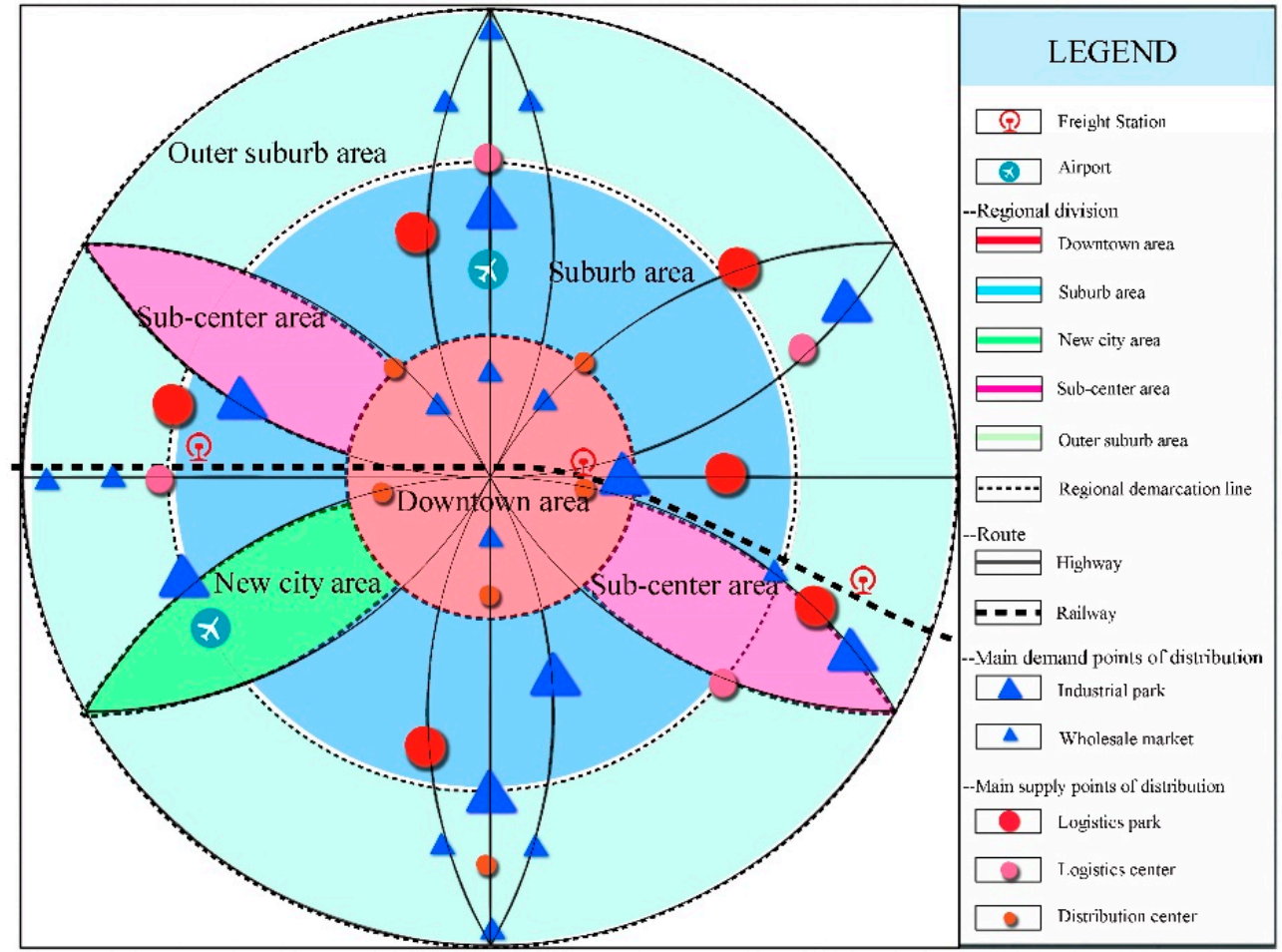

Figure 8. The general characteristics of the distribution pattern of large cities in China.

\subsection{Supply and Demand Characteristics and Type Division in 17 Typical Cities}

The authors calculated the distribution demand amount, point distribution supply capacity, and road distribution supply capacity in 2013 for the 17 sampled cities by using the computational Formulas (1)-(3) (see Figure 9). The main data are shown in Appendix A. In the calculation process, the average daily traffic capacity of one lane is 20,000 according the CJJ 37-2012 Code for design of City Road Engineering. The node and road capacity are transformed through a 1.5-ton standard truck.

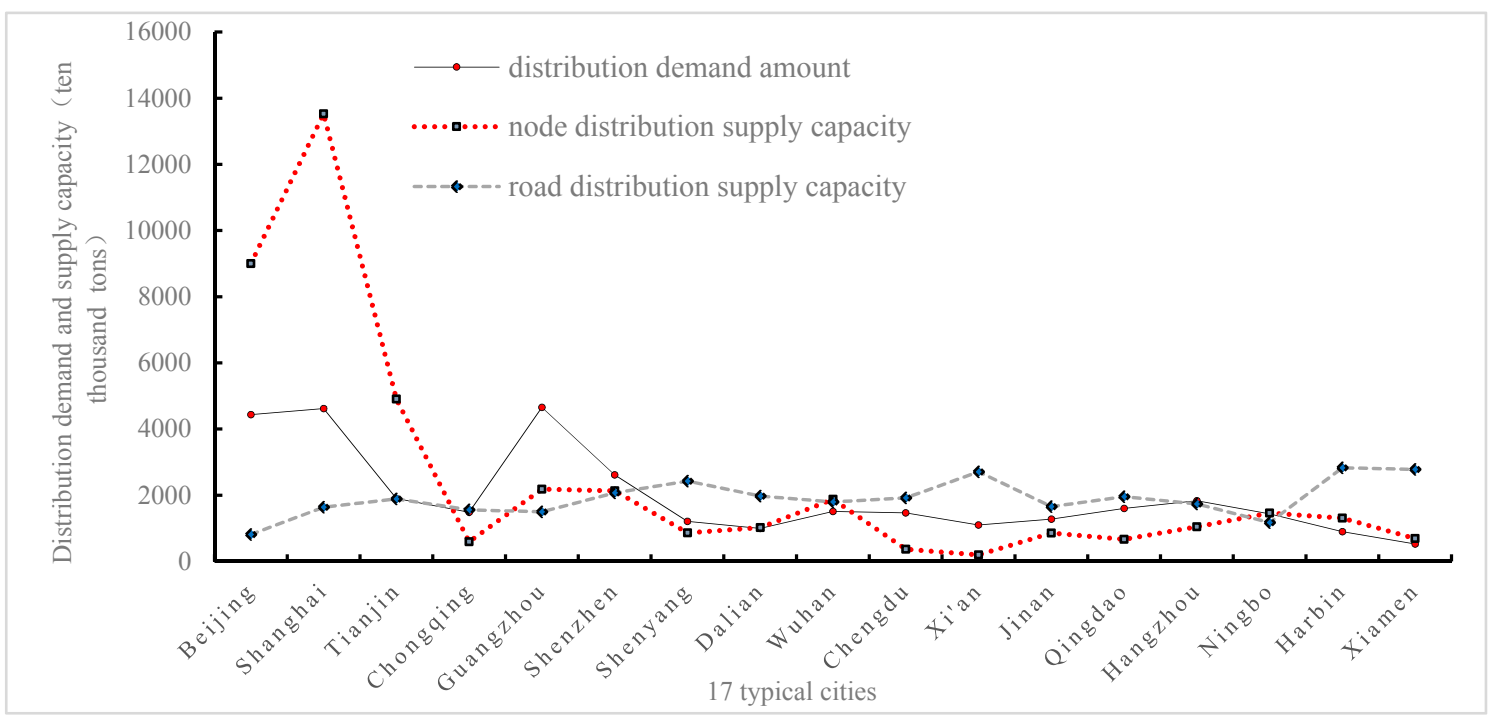

Figure 9. Distribution demand and supply capacity in 17 typical cities.

Based on the results of Figure 9, D signifies the distribution demand amount; $\mathrm{S}$ signifies the road distribution supply capacity, and S' signifies the node distribution supply capacity. The 17 typical cities 
can be divided into three categories of areas, namely, highly unbalanced, unbalanced, and balanced ones, in light of the matching degree of supply and demand. The division results are shown in Table 4 .

Table 4. Division results based on the matching degree of supply and demand. D: distribution demand amount; S: road distribution supply capacity, and $S^{\prime}$ : node distribution supply capacity.

\begin{tabular}{ccc}
\hline Category & Standards & Results \\
\hline Highly unbalanced areas & $\mathrm{S}^{\prime} / \mathrm{D}>2$, or $\mathrm{S} / \mathrm{D}$ and $\mathrm{S}^{\prime} / \mathrm{D}<1$ & $\begin{array}{c}\text { Beijing, Shanghai, Guangzhou, } \\
\text { Shenzhen, Tianjin, Hangzhou }\end{array}$ \\
\hline Balanced areas & S/D and S' $/ \mathrm{D}>1$ & Dalian, Wuhan, Harbin, Xiamen \\
\hline Unbalanced areas & - & $\begin{array}{c}\text { Chongqing, Chengdu, Shenyang, } \\
\text { Xi'an, Ji'nan, Qingdao, Ningbo }\end{array}$ \\
\hline
\end{tabular}

(1) Highly unbalanced areas: This category of areas is located in Beijing, Shanghai, Guangzhou, Shenzhen, etc. in the Pearl River Delta, Yangtze River Delta, and Beijing-Tianjin-Hebei region, respectively. In these areas, the supply capacity of its distribution roads is far from meeting the demands of the city distribution. Especially in the three traditional first-tier cities (Beijing, Shanghai, and Guangzhou), the road supply capacity only meets $18.4 \%$, 35.5\%, and $32.2 \%$ of the demand, respectively, and the three metropolises have huge permanent resident populations, high per capita disposable incomes, high urbanization levels, good e-commerce development environments, and relatively strong radiation abilities. Moreover, the supply capacities of distribution points at Beijing, Shanghai, Tianjin are respectively 2.03, 2.93, and 2.58 times of the distribution demand amounts, which is consistent with the four cities' roles as centers of the regional economy, commerce, and trade, and their respective functions as port cities.

(2) Unbalanced areas: These areas are located in Chongqing, Chengdu, Xi'an, Ji'nan, etc. in West China, the Liaodong Peninsula Area, and Northeast China, respectively. In this category of areas, the configuration of node and road capacities is uncoordinated. For instance, in such major cities in West China as Chongqing, Chengdu, and $\mathrm{Xi}^{\prime}$ an, their node capacities account for $40.2 \%, 25.3 \%$, and $18.3 \%$ of the city distribution demands, respectively, while their road capacities exceed the distribution service demands. It indicates that the city distribution network systems in the above areas are not yet fully developed, and the shortage of their point capacities restricts their road capacities, failing to promote their roles of radiation and motivation in the surrounding areas. In the above cities, their urbanization levels are low, they have medium per capita disposable income, their logistics efficiency is not high, and they have less technical equipment.

(3) Balanced areas: These areas are located in such cities as Wuhan, Xiamen, and Dalian in Central China, and the coastal areas in the southeast and northeast parts of China, respectively. In these cities, the node and road capacities are complementary to each other and close to the demands. With relatively complete city distribution network systems, the cities with ports have sufficient land resources logistics. They have a sparse permanent resident population and multiple city centers. For instance, the resident populations of Dalian and Xiamen are 694 million and 373 million, respectively, ranking the penultimate first and second among 17 central cities in China. Although the population of Wuhan exceeds 10.22 million, it is scattered in three areas: Wuchang, Hankou, and Hanyang.

In the downtown areas of the 17 cities, the population and commercial densities are much higher than their respective averages of the whole cities [48]. For example, the densities in the downtown areas are 22.76 times that of the average in Tianjin, 19 times that of Beijing, and more than 10 times that of Shenyang, Jinan, and Qingdao; and the number and scale of commercial facilities in the downtown areas accounted for more than $95 \%$ of these cities' total. As a result, the distribution supply in downtown areas is still far from meeting the demand, and it is difficult to effectively 
solve the distribution problems in the short-term [2]; new management methods and strategies are urgently needed.

\section{Sustainable Distribution Model Design}

From the perspective of the supply-demand theory in economics and the supply-demand analysis of transportation systems $[79,80]$, the core of distribution problems in large cities lies in the imbalance between supply and demand. Its impact on city sustainable development is reflected in:

(1) The number of delivery trucks and increase in energy consumption during the distribution process. The increased demand for distribution, as well as the service characteristics of multi-frequency and small-volume in delivery, has led to a sharp increase in the number of distribution trucks [25]. Under the strict cargo management policy of large cities, large trucks are difficult to enter downtown areas during the daytime, and a large amount of goods are transferred to small box trucks, which not only increases the loading and unloading times, but also easily leads to the idling of the vehicles [19].

(2) The conflict between distribution space and living space has intensified. Due to the increase in land prices and the reduction of logistics land in downtown areas, distribution supply facilities are gradually decreasing [47]. At the same time, distribution demands are concentrated in city centers, which leads to the existence of large number of non-compliant distribution spaces, being a serious safety concern in the living space. These safety hazards are extremely likely to cause major accidents.

(3) Unreasonable and over delivery has been around for a long time. Poor communication leads to the widespread of a large number of non-real needs. Secondly, delivering returned goods from impulsive consumption and the amplification of real distribution demands have put tremendous pressure on the existing supply facilities. In addition, a lack of comprehensive understanding of distribution needs and road network conditions stimulate problems such as vehicle idling and excessive delivery, which are reflections of the imbalance between supply and demand [81].

Under the circumstances that the road supply capacities in China's bigger cities are basically saturated and the distribution demand is growing rapidly, it is difficult to solve the problems of distribution in a short period of time [2]. From a spatial differentiation perspective, this paper propose a sustainable distribution model based on supply and demand coordination.

\subsection{Demand Management Based on Type and Area Differentiation}

Through the establishment of a large data platform for the collection and monitoring of distribution demand of terminal customers (residential and commercial facilities, etc.), the authors can better understand the amount, type, time, source, and service object of demands, and clarify their spatial and temporal distribution characteristics. For different types of demands in different areas of the city, the differentiating management measures are as follows:

(1) Downtown and suburb areas: These areas need to meet the basic living demands; control and limit hedonic demand; reduce the demands for redundant construction, excessive greening, and excessive lighting; and restrain other demands derived from the residents' leisure and entertainment. Some living consumption and business service demands in downtown and suburb areas need to be gradually transferred to the outer suburb and subcenter areas, which is an important way to reduce traffic pressure and pollution problems in the downtown and suburb areas.

(2) Subcenter areas and new city areas: These areas have ample logistics land, and land prices are relatively low. An excessive concentration of demand and supply can be avoided through planning in advance. Hedonic and business service demands in downtown and suburb areas can be transferred to subcenter and new city areas, where logistics nodes and transportation hubs can be built, and new industrial parks and wholesale markets can be established.

(3) Outer suburb areas: Commercial facilities and terminal distribution nodes shall be planned and established to increase the satisfaction rate of demand over time. To attract population and commercial facilities, the level of distribution service in the outer suburb areas will be enhanced. In the future, the outer suburb areas will be dedicated to the satisfaction of industrial demand and become the 
transit area for intercity distribution needs. Large distribution centers will be planned and built here. Establishing differentiated demand management methods for different areas of the city helps reduce demand density, improve demand management efficiency, and improve distribution service levels.

\subsection{Supply Management Based on Technology, Model Innovation}

Without a significant increase in the existing distribution supply capacity, how to solve the imbalance between the supply and demand of distribution with modern technology and model innovation remains a problem $[82,83]$. In this process, the government should issue policies to guide the development into proper channels [48]. Enterprises should actively explore new service models and invest in new technical equipment. For example, through the real-time acquisition and dynamic monitoring of status indicators such as the capacity and speed of key facilities and main roads, the point-to-road capability can be quickly promoted, and supply efficiency can be improved. The main strategies include the following:

(1) Platform strategy: Firms and enterprises should be encouraged to establish truck and cargo matching platforms and terminal distribution platforms represented by "Truck alliance", "Huolala", "Ishansong", etc. With dynamic matching models and algorithms for supply and demand, the status of real-time supply can be monitored, and the amount of demand can be forecast dynamically. This will help reduce the problem of vehicle idling and space underutilization caused by information asymmetry, and provide exemplary models for the layout and adjustment of terminal distribution facilities.

(2) Collaboration strategy: With the implementation of the pilot collaborated distribution projects sponsored by the Ministry of Commerce and Ministry of Finance, different cities should formulate action plans for collaboration in distribution in accordance with their actual conditions, in which enterprises should play the leading role. The governments' favorable policies shall be made use of in purchasing public services, and the public-private cooperation model shall be established. With incentives given to the establishment of distribution alliances among companies in the same industry and across industries, distribution supply capacity can be maximized for the convenient and effective movement of vehicles in distribution activities.

(3) Green strategy: Taking advantage of existing high-speed rail freight and large-scale metro network in Chinese large cities [84,85], the feasibility of adding special trains for distribution in metro lines and intercity rail lines can be explored, and the use of vans in downtown areas can be reduced. Moreover, the efficiency of supply can be significantly improved with the introduction and wider application of new energy trucks, unmanned vehicles, and drone distribution, and green recyclable packaging can also greatly cut down the energy consumption of distribution.

The goal of supply management is to improve quality and efficiency, increase the real-time responsiveness to demand, and reduce environmental pollution and the waste of resources in the service process. The main guiding strategies for different types of requirements in different spaces, as well as the platform, collaboration, and green strategies, are shown in Figure 10. The results include a reduction in the number of traditional freight trucks and increase in green packaging and new energy trucks. The demands for distribution in suburban and new city areas will concentrate, while those in the downtown areas will decrease. 


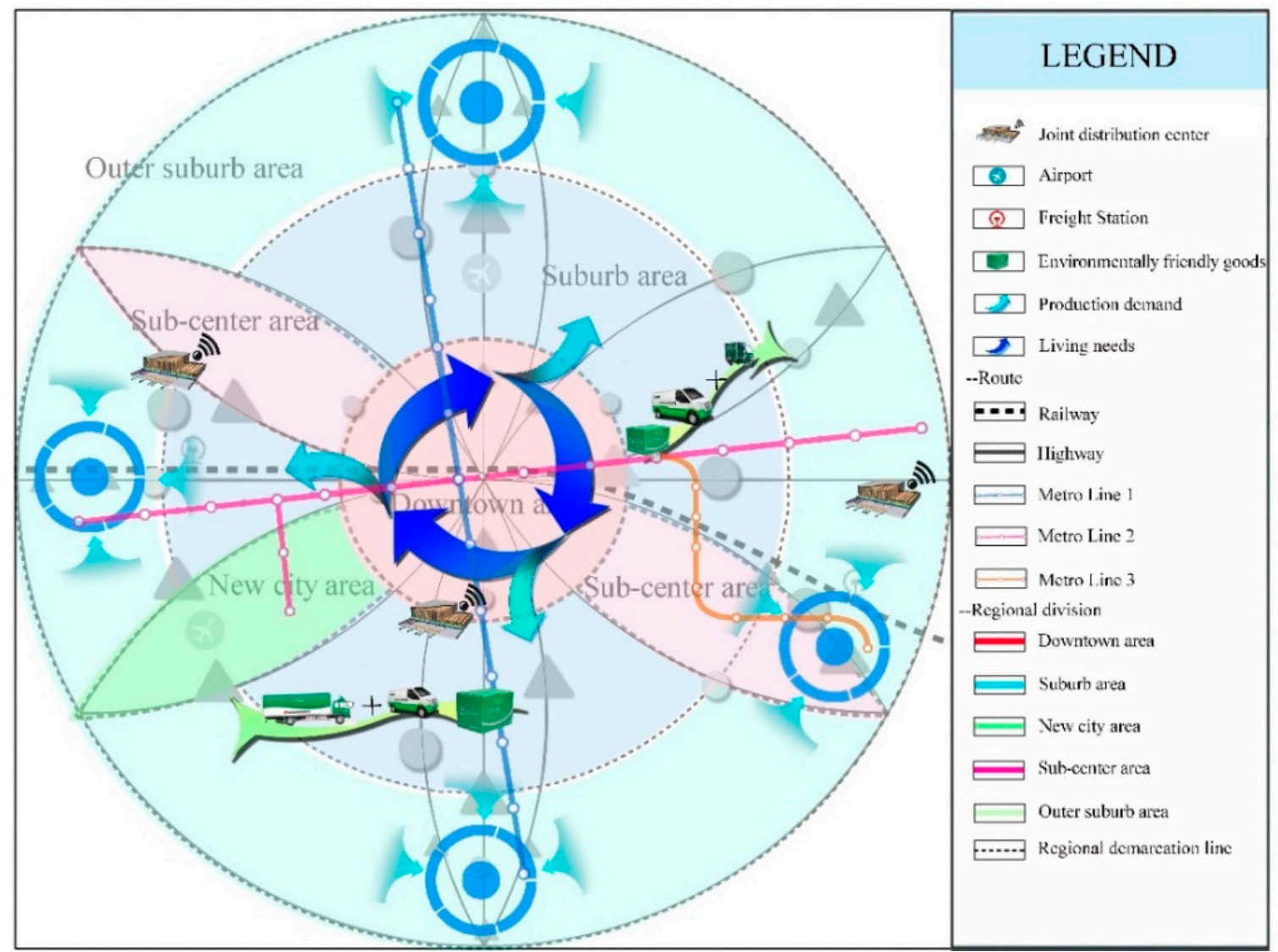

Figure 10. Sustainable distribution model design based on supply-demand coordination.

The expected goals after the implementation of the supply and demand management strategies include:

(1) If $10 \%$ of the 17 sample city's distribution demand (about 35,000 tons) is borne by new energy vehicles and metro lines and intercity rail lines, it is expected to reduce the number of transports of box trucks (loading capacity: 3.5 tons) by 10,000 times. This is also effective in reducing energy consumption and carbon emissions, while the pressure of urban road traffic is mitigated $[30,86]$. To achieve this goal, the Ministry of Transport, Commerce, and Public Security of China have organized 22 cities including Tianjin, Shijiazhuang, and Chengdu to develop themselves into Pilot Cities for Green Freight Distribution in 2018. At the same time, JD and Alibaba also released a green smart logistics vehicle plan and planned to purchase a large number of new energy trucks. By 2017, a total of 34 cities in China's mainland have completed the construction of $5021.7 \mathrm{~km}$ of city rail transit routes, and such routes in the 17 sample cities accounted for more than $80 \%$ of the total. This provides an important foundation for city distribution, and its technical, economic, and environmental feasibility has been fully justified $[85,87]$.

(2) In 2011, the Ministry of Commerce of China began to implement a joint distribution action plan, which proposed that the core city's joint distribution (including unified distribution) network coverage rate should reach $40 \%$, and freight volume by truck decrease by $30 \%$. Under this circumstance, the 17 sample cities were included in the joint distribution of pilot cities. If the joint distribution accounts for $5 \%$ (about 15,000 tons) of the total distribution demand, the number of transports of box trucks (loading capacity: 3.5 tons) is expected to reduce by 5000 times. This is in full compliance with the needs of China's online retail development, but how to set up a common distribution center will become a key issue to be solved urgently $[33,88]$. 
(3) Consider that the population and commercial density of the downtown areas of China's big cities are 5-10 times that of the entire city [2]; tremendous pressure is thus imposed on the last mile distribution [10,48], and it also brought serious shortages of road resources and space conflicts [89]. If $10 \%$ of the distribution demand of the downtown areas is shifted to the suburb areas and subcenters of the city, the annual distribution will be reduced by 20,000 tons, and the number of transports of box trucks (loading capacity: 3.5 tons) will be reduced by more than 5700 times.

Of course, the implementation of the above-mentioned strategies requires the government to coordinate the interests of the participating entities, formulate an annual action plan in accordance with the goals of sustainable development and low-carbon constraints, and encourage enterprises to actively fulfill their social responsibilities.

\section{Conclusions and Discussion}

Under the multiple constraints of population, resources, and the environment, the issue of sustainable development in big cities has received widespread attention, which is inevitably influenced by important factors such as the equilibrium of economic development, social welfare, resource consumption, environmental pollution, and governance. As a derivative demand for social and economic development, urban distribution plays a positive role in ensuring the consumption of urban and rural residents and promoting the city's economic growth. However, environmental pollution, traffic congestion, resource consumption, and other problems of urban distribution have been restricting sustainable urban development, and can never be ignored. This paper selected 17 typical cities with some major difficulties in distribution in China as the empirical study objects, identified the characteristics and spatial differences of distribution and supply in China's big cities, and provided a new perspective for the world's observation of China's urban distribution management.

The innovation of this study is the integration of online data and economic census data. Through correlation analysis, the study shows the reliability of the data and overcomes the deficiency in distribution data in China. With the existing demand forecast and the evaluation indexes of supply capacity, the calculation methods of distribution demand and supply are developed, and the interactive relationship between supply and demand in different cities is quantified. From the perspective of spatial differentiation, the authors designed an innovative distribution management mode based on supply and demand coordination in large Chinese cities.

\subsection{Conclusions}

(1) The spatial distribution of logistics space in large cities in China displays a multicenter pattern, featuring scattered demand and relatively concentrated supply. The freight generation activities and supply infrastructure are located in different parts of the cities. For example, the distribution centers are mainly located between the downtown and suburban areas, while larger logistics facilities such as logistics centers and parks are farther away from the city centers. This is consistent with the trend of logistics sprawl in cities in Europe and the United States. The dynamic changes in logistics space are also subject to the development of subcenters and new urban areas in China's large cities, and such changes can help alleviate the contradiction between supply and demand of distribution through space management.

(2) The contradiction between supply and demand is prevalent in the 17 sample cities. The higher the rate of economic growth, the more prominent the single-center pattern of cities, and the more significant the contradiction between supply and demand becomes. As the focus of urban distribution management, central cities are the key to measuring the effectiveness of distribution management. Since existing urban road resources are seriously insufficient, the priority is given to passenger transport, and restrictions on the shipping time and area of freight traffic are inevitable. The multicentered supply and demand space of urban distribution provides a new way to mitigate the conflict between urban supply and demand. 
(3) In the design of sustainable distribution model, the authors of this paper propose that governments should start with differentiated demand management, promote the gradual transfer of living demand to the suburb areas, and transfer the productive demand to the new city areas and subcenter areas. This will effectively reduce the non-compliant distribution space and the density of distribution demand in the downtown areas. With the implementation of platform development, collaboration, and green strategies, supply efficiency and capacity will be improved, distribution costs will be reduced, and space conflicts between the urban distribution, production, and living activities can be pacified. This management model innovation draws on the useful experience of foreign city distribution management, which not only conforms to China's national conditions, but also effectively utilizes advanced technological means.

\subsection{Discussions}

(1) Existing researches show that the distribution problems faced by large cities in developed countries are mainly traffic congestion, environmental pollution, and late deliveries. The strategy is to use information technology to rationally optimize the distribution route, reduce the use of trucks in the distribution process, and achieve the punctuality of distribution. At present, there are more technological innovations for the "last-mile distribution". As an emerging developing country, the essence of China's large city distribution problem lies in the serious imbalance between supply and demand, especially in different areas of the city, which requires a new perspective in distribution management. With the redistribution of demand and the improvement of the supply technology level, new supply and demand balance points can be found in different areas of the city.

(2) China is relocating its rural population into large cities and accelerating the reconstruction of large cities. This poses a huge challenge to city distribution management. At the same time, the rapid flow of population, resources, and production elements, as well as the swift growth of the internet economy, especially the integration of online and offline consumption, provides an important opportunity to optimize city distribution management and control demand effectively. A large number of empirical studies have shown that there are similar spatial patterns in major bigger cities around the world. Thus, the distribution space pattern developed and the differentiated demand management strategies proposed in this paper are significant for the distribution management of metropolises in developed countries.

(3) Since China's logistics industry has not entered the industrial classification codes to date, the national statistical data are not complete, and the data that characterizes the distribution supply and demand mainly comes from consulting companies and big data logistics companies. The POI data and national economic census data can be used to quantify the relationship between supply and demand. This study primarily adopts cross-section data rather than long-period panel data, which will also have a certain impact on the understanding of the evolution law and intrinsic mechanism of supply and demand characteristics. The shortcomings of the above research need to be further explored in the next stage of work. With the continuously increasing environmental pressures, it is particularly important to quantify the efficiency of the new technology and business model innovation to improve the supply capacity and efficiency.

(4) At last, in order to test the effectiveness of the sustainable distribution strategy proposed in this paper, significant further empirical research is needed. This is very important for the big cities in China in the process of rapid urbanization. It can also provide exemplary models for urban distribution management in Brazil, India, and other countries.

Author Contributions: Methodology, S.L.; Data curation, S.L. and G.L.; Visualization, D.L.; Writing-original draft, S.L. and G.L.; Writing-review \& editing, J.X., G.L. and X.S.; All authors read and approved the final manuscript.

Funding: This research is supported by the National Natural Science Foundation of China (Grant No. 41501123; 71603219), the Fundamental Research Funds for the Central Universities of China (Grant No. 2682016CX051) and the Soft Science Research Projects of Science and Technology Office of Sichuan Province (Grant No. 2018ZR0100). 
Conflicts of Interest: The authors declare no conflict of interest.

\section{Abbreviations}

The following abbreviations are used in this manuscript:

$\begin{array}{ll}\text { BESTUFS } & \text { Best urban freight solutions } \\ \text { POI } & \text { Point of Interest } \\ \text { OD } & \text { origin-destination } \\ \text { GPS } & \text { Global Positioning System } \\ \text { W\&D } & \text { Warehouse and distribution } \\ \text { MIT } & \text { Massachusetts Institute of Technology } \\ \text { API } & \text { application programming interface } \\ \text { aEDI } & \text { Alibaba E-commerce Development Index } \\ \text { CJFD } & \text { China Academic Journals Full-text Database }\end{array}$

\section{Appendix}

Table A1. Basic data of demand and supply of distribution in 17 typical cities.

\begin{tabular}{cccccccccccc}
\hline City & $\boldsymbol{m}_{\boldsymbol{i}}$ & $\boldsymbol{n}_{\boldsymbol{i}}$ & $\boldsymbol{p}_{\boldsymbol{i}}$ & $\boldsymbol{\lambda}_{\boldsymbol{i}}$ & $\boldsymbol{\rho}_{\boldsymbol{i}}$ & $\boldsymbol{s}_{\boldsymbol{i}}$ & $\boldsymbol{l}_{\boldsymbol{i}}$ & $\boldsymbol{q}_{\boldsymbol{i}}$ & $\boldsymbol{q}_{\boldsymbol{i}}^{\prime}$ & $\boldsymbol{s}_{\boldsymbol{i}}^{\prime}$ & $Q_{\boldsymbol{i}}$ \\
\hline Beijing & 8375.1 & $190,704.0$ & 2114.8 & $40,321.0$ & 42.9 & $13,884.0$ & 7931.0 & 25.7 & 518.9 & 35.0 & $25,889.0$ \\
Shanghai & 8019.1 & $145,668.0$ & 2415.2 & $43,851.0$ & 38.4 & 9932.0 & 4865.0 & 20.1 & 235.1 & 85.5 & $43,809.0$ \\
Tianjin & 4470.4 & $66,133.0$ & 1472.7 & $32,658.0$ & 25.2 & $12,440.0$ & 6933.0 & 24.3 & 216.6 & 55.0 & $31,985.0$ \\
Chongqing & 4511.8 & $80,577.0$ & 2970.0 & $25,216.0$ & 17.0 & $12,723.0$ & 6221.0 & 31.7 & 389.9 & 19.3 & $71,842.0$ \\
Guangzhou & 6882.9 & $65,154.0$ & 1292.7 & $42,066.0$ & 46.0 & $10,241.0$ & 7127.0 & 27.6 & 247.7 & 18.5 & $59,142.0$ \\
Shenzhen & 4433.6 & $84,245.0$ & 1062.9 & $44,653.0$ & 50.2 & $11,496.0$ & 6364.0 & 31.6 & 258.1 & 12.1 & $22,242.0$ \\
Shenyang & 3186.1 & $35,801.0$ & 825.7 & $29,074.0$ & 22.2 & 7777.0 & 3527.0 & 14.7 & 125.3 & 10.0 & $20,957.0$ \\
Dalian & 2526.5 & $32,284.0$ & 694.3 & $30,238.0$ & 31.5 & 8384.0 & 3025.0 & 15.5 & 106.2 & 18.0 & $26,276.0$ \\
Wuhan & 3878.6 & $40,849.0$ & 1022.0 & $29,821.0$ & 29.0 & 7443.0 & 4833.0 & 14.6 & 132.1 & 20.7 & $25,023.0$ \\
Chengdu & 3752.9 & $22,346.0$ & 1429.8 & $29,968.0$ & 28.8 & 7017.0 & 2707.0 & 19.4 & 256.0 & 7.2 & $42,537.3$ \\
Xi'an & 2548.0 & $24,205.0$ & 858.8 & $33,100.0$ & 24.9 & 7452.0 & 3081.0 & 20.7 & 163.5 & 6.0 & $49,243.0$ \\
Jinan & 2743.4 & $32,093.0$ & 699.9 & $35,648.0$ & 24.3 & 7859.0 & 4749.0 & 13.7 & 121.4 & 7.9 & $17,570.0$ \\
Qingdao & 2904.3 & $52,523.0$ & 896.4 & $35,227.0$ & 46.4 & 5426.0 & 4334.0 & 17.5 & 152.5 & 6.6 & $23,720.0$ \\
Hangzhou & 3531.2 & $68,329.0$ & 884.4 & $39,310.0$ & 32.2 & 2869.0 & 2479.0 & 17.3 & 204.7 & 9.1 & $23,884.0$ \\
Ningbo & 2635.7 & $41,753.0$ & 766.3 & $41,729.0$ & 31.5 & 8384.0 & 1582.0 & 9.8 & 142.1 & 12.1 & $17,790.0$ \\
Harbin & 2728.3 & $17,803.0$ & 1065.6 & $25,197.0$ & 17.3 & 5767.0 & 2761.0 & 14.5 & 100.5 & 8.8 & 9007.0 \\
Xiamen & 974.5 & $25,761.0$ & 373.0 & $41,360.0$ & 38.6 & 3570.0 & 1777.0 & 10.0 & 67.7 & 8.2 & 9393.0 \\
\hline
\end{tabular}

\section{References}

1. Dablanc, L. Goods transport in large European cities: Difficult to organize, difficult to modernize. Transp. Res. Part A 2007, 41, 280-285. [CrossRef]

2. Li, G.; Liu, S. Delivery Problems and Strategies in Large Cities. Urban Transp. China 2016, 14, 77-82.

3. O'Connor, K. Global city regions and the location of logistics activity. J. Transp. Geogr. 2010, 18, 354-362. [CrossRef]

4. Van den Heuvel, F.P.; de Langen, P.W.; van Donselaar, K.H.; Fransoo, J.C. Regional logistics land allocation policies: Stimulating spatial concentration of logistics firms. Transp. Policy 2013, 30, 275-282. [CrossRef]

5. Giuliano, G.; Kang, S. Spatial dynamics of the logistics industry: Evidence from California. J. Transp. Geogr. 2018, 66, 248-258. [CrossRef]

6. Aljohani, K.; Thompson, R.G. Impacts of logistics sprawl on the urban environment and logistics: Taxonomy and review of literature. J. Transp. Geogr. 2016, 57, 255-263. [CrossRef]

7. Swamy, S.; Baindur, D. Managing urban freight transport in an expanding city-Case study of Ahmedabad. Res. Transp. Bus. Manag. 2014, 11, 5-14. [CrossRef]

8. Marujo, L.G.; Goes, G.V.; D'Agosto, M.A.; Ferreira, A.F.; Winkenbach, M.; Bandeira, R.A.M. Assessing the sustainability of mobile depots: The case of urban freight distribution in Rio de Janeiro. Transp. Res. Part $D$ 2018, 62, 256-267. [CrossRef] 
9. Oliveira, L.K.; Barraza, B.; Bertocini, B.V.; Isler, C.A.; Pires, D.R.; Madalon, E.C.N.; Lima, J.; Vieira, J.G.V.; Meira, L.H.; Bracarense, L.S.F.P. An Overview of Problems and Solutions for Urban Freight Transport in Brazilian Cities. Sustainability 2018, 10, 1233. [CrossRef]

10. Faccio, M.; Gamberi, M. New City Logistics Paradigm: From the "Last Mile" to the "Last 50 Miles" Sustainable Distribution. Sustainability 2015, 7, 14873-14894. [CrossRef]

11. Oliveira, C.M.D.; Goes, G.V.; Gonçalves, D.N.S.; D’Agosto, M.D.A. Sustainable Vehicles-Based Alternatives in Last Mile Distribution of Urban Freight Transport: A Systematic Literature Review. Sustainability 2017, 9, 1324. [CrossRef]

12. Van Binsbergen, A.; Visser, J. Innovation Steps towards Efficient Goods Distribution Systems for Urban Areas; Delft University Press: Amsterdam, The Netherlands, 2001.

13. Cherrett, T.; Allen, J.; Mcleod, F.; Maynard, S.; Hickford, A.; Browne, M. Understanding urban freight activity-Key issues for freight planning. J. Transp. Geogr. 2012, 24, 22-32. [CrossRef]

14. Wątróbski, J.; Małecki, K.; Kijewska, K.; Iwan, S.; Karczmarczyk, A.; Thompson, R. Multi-Criteria Analysis of Electric Vans for City Logistics. Sustainability 2017, 9, 1453. [CrossRef]

15. Ranieri, L.; Digiesi, S.; Silvestri, B.; Roccotelli, M. A Review of Last Mile Logistics Innovations in an Externalities Cost Reduction Vision. Sustainability 2018, 10, 782. [CrossRef]

16. Rodrigue, J.-P.; Dablanc, L.; Giuliano, G. The Freight Landscape: Convergence and Divergence in Urban Freight Distribution. J. Transp. Land Use 2017, 10, 557-572. [CrossRef]

17. Yang, L.; Cai, Y.; Hong, J.; Shi, Y.; Zhang, Z. Urban Distribution Mode Selection under Low Carbon Economy-A Case Study of Guangzhou City. Sustainability 2016, 8, 673. [CrossRef]

18. Li, G.; Jin, F.; Jiao, J.; Liu, S. Location characteristics and differentiation mechanism of logistics nodes and logistics enterprises based on points of interest (POI): A case study of Beijing. J. Geogr. Sci. 2017, 27, 879-896. [CrossRef]

19. Yang, J.; Guo, J.; Ma, S. Low-carbon city logistics distribution network design with resource deployment. J. Clean. Prod. 2013, 119, 223-228. [CrossRef]

20. Zhao, P. Sustainable urban expansion and transportation in a growing megacity: Consequences of urban sprawl for mobility on the urban fringe of Beijing. Habitat Int. 2010, 34, 236-243. [CrossRef]

21. Zacharias, J.; Zhang, B. Local distribution and collection for environmental and social sustainabilityTricycles in central Beijing. J. Transp. Geogr. 2015, 49, 9-15. [CrossRef]

22. Guo, J.; Wang, X.; Fan, S.; Gen, M. Forward and reverse logistics network and route planning under the environment of low-carbon emissions. Comput. Ind. Eng. 2017, 106, 351-360. [CrossRef]

23. Zhu, X.; Li, R. An Analysis of Decoupling and Influencing Factors of Carbon Emissions from the Transportation Sector in the Beijing-Tianjin-Hebei Area, China. Sustainability 2017, 9, 722. [CrossRef]

24. Mahpula, A.; Yang, D.; Kurban, A.; Witlox, F. An overview of 20 years of Chinese logistics research using a content-based analysis. J. Transp. Geogr. 2013, 31, 30-34. [CrossRef]

25. Hayashi, K.; Nemoto, T.; Nakaharai, S. The Development of the Parcel Delivery Service and its Regulations in China. Procedia Soc. Behav. Sci. 2014, 125, 186-198. [CrossRef]

26. Wang, J.J.; Xiao, Z. Co-evolution between etailing and parcel express industry and its geographical imprints: The case of China. J. Transp. Geogr. 2015, 46, 20-34. [CrossRef]

27. Wang, G.; Gunasekaran, A.; Ngai, E.W.T.; Papadopoulos, T. Big data analytics in logistics and supply chain management: Certain investigations for research and applications. Int. J. Prod. Econ. 2016, 176, 98-110. [CrossRef]

28. Bányai, T. Real-Time Decision Making in First Mile and Last Mile Logistics: How Smart Scheduling Affects Energy Efficiency of Hyperconnected Supply Chain Solutions. Energies 2018, 11, 1833. [CrossRef]

29. Crainic, T.G.; Perboli, G.; Rosano, M. Simulation of intermodal freight transportation systems: A taxonomy. Eur. J. Oper. Res. 2018, 270, 401-418. [CrossRef]

30. Musolino, G.; Rindone, C.; Polimeni, A.; Vitetta, A. Planning urban distribution center location with variable restocking demand scenarios: General methodology and testing in a medium-size town. Transp. Policy 2018, in press. [CrossRef]

31. Holguín-Veras, J.; Hodge, S.; Wojtowicz, J.; Singh, C.; Wang, C.; Jaller, M.; Aros-Vera, F.; Ozbay, K.; Weeks, A.; Replogle, M. The New York City Off-Hour Delivery Program: A Business and Community-Friendly Sustainability Program. Interfaces 2018, 48, 70-86. [CrossRef] 
32. Arvidsson, N.; Pazirandeh, A. An ex ante evaluation of mobile depots in cities: A sustainability perspective. Int. J. Sustain. Transp. 2017, 11, 623-632. [CrossRef]

33. He, Y.; Wang, X.; Lin, Y.; Zhou, F.; Zhou, L. Sustainable decision making for joint distribution center location choice. Transp. Res. Part D 2017, 55, 202-216. [CrossRef]

34. Nuzzolo, A.; Comi, A. Urban freight demand forecasting: A mixed quantity/delivery/vehicle-based model. Transp. Res. Part E 2014, 65, 84-98. [CrossRef]

35. Onieva, L. Modelling peak-hour urban freight movements with limited data availability. Comput. Ind. Eng. 2010, 59, 34-44.

36. Nuzzolo, A.; Comi, A.; Ibeas, A.; Moura, J.L. Urban freight transport and city logistics policies: Indications from Rome, Barcelona, and Santander. Int. J. Sustain. Transp. 2016, 10, 552-566. [CrossRef]

37. Lindholm, M.; Behrends, S. Challenges in urban freight transport planning-A review in the Baltic Sea Region. J. Transp. Geogr. 2012, 22, 129-136. [CrossRef]

38. Macharis, C.; Kin, B. The 4 A's of sustainable city distribution: Innovative solutions and challenges ahead. Int. J. Sustain. Transp. 2016, 11, 59-71. [CrossRef]

39. Yang, H.L.; Liu, C.J.; Zhang, Q.N. Study on the Demand and Supply of Urban Logistics. Logist. Technol. 2007, $26,50-53$.

40. Zhang, J. Logistics Planning Principles and Methods; Southwest Jiaotong University Press: Chengdu, China, 2009.

41. Kin, B.; Verlinde, S.; Macharis, C. Sustainable urban freight transport in megacities in emerging markets. Sustain. Cities Soc. 2017, 32, 31-41. [CrossRef]

42. Mesa-Arango, R.; Ukkusuri, S.V. Demand clustering in freight logistics networks. Transp. Res. Part E 2015, 81, 36-51. [CrossRef]

43. Buldeo Rai, H.; Verlinde, S.; Merckx, J.; Macharis, C. Crowd logistics: An opportunity for more sustainable urban freight transport? Eur. Transp. Res. Rev. 2017, 9, 39. [CrossRef]

44. Marcucci, E.; Gatta, V. Investigating the potential for off-hour deliveries in the city of Rome: Retailers' perceptions and stated reactions. Transp. Res. Part A 2017, 102, 142-156. [CrossRef]

45. Lagorio, A.; Pinto, R.; Golini, R. Research in urban logistics: A systematic literature review. Int. J. Phys. Distr. Log. 2016, 46, 908-931. [CrossRef]

46. Dablanc, L.; Ogilvie, S.; Goodchild, A. Logistics Sprawl: Differential Warehousing Development Patterns in Los Angeles and Seattle. Transp. Res. Rec. 2014, 2410, 105-112. [CrossRef]

47. Liu, S.J.; Li, G.Q.; Jin, F.J. Location choice behaviors and hierarchical differences of star warehouses in China. Prog. Geogr. 2017, 36, 843-852.

48. Russo, F.; Comi, A. Urban Freight Transport Planning towards Green Goals: Synthetic Environmental Evidence from Tested Results. Sustainability 2016, 8, 381. [CrossRef]

49. Russo, F.; Comi, A. The Simulation of Shopping Trips at Urban Scale: Attraction Macro-Model. Procedia Soc. Behav. Sci. 2012, 39, 387-399. [CrossRef]

50. Gentile, G.; Vigo, D. Movement generation and trip distribution for freight demand modelling applied to city logistics. Eur. Transp. Trasp. Eur. 2013, 54,1-27.

51. Comi, A.; Nuzzolo, A. Simulating Urban Freight Flows with Combined Shopping and Restocking Demand Models. Procedia Soc. Behav. Sci. 2014, 125, 49-61. [CrossRef]

52. Yu, D.; Qi, F.Z. The Model of Highway Logistic Demand Forecasting Based on Gray Neural Network. Soft Sci. 2009, 23, 132-135.

53. Guo, W.; Xu, Q.; Xu, X.L. Forecasting of Regional Logistics' Supply and Demand in the "One Belt and One Road" Areas: Based on Sinkiang and Fujian provinces' Data. Spec. Zone Econ. 2016, 3, 23-25.

54. Zhang, Y.F. Analysis of the Coordination between Regional Logistics Supply and Demand Based on Coupling Model: A Case Study of Henan. J. Zhongyuan Univ. Technol. 2017, 6, 86-90.

55. Hu, Z.; Zhang, Y.; Yao, L. Radial Basis Function Neural Network with Particle Swarm Optimization Algorithms for Regional Logistics Demand Prediction. Discret. Dyn. Nat. Soc. 2014, 2014, 189-192. [CrossRef]

56. Kijewska, K.; Iwan, S.; Konicki, W.; Kijewski, D. Assessment of freight transport flows in the city centre based on the Szczecin example-Methodological approach and results. Res. Transp. Bus. Manag. 2017, 24, 59-72. [CrossRef]

57. Lu, B.; Wang, S.; Kuang, H. Forecast of regional logistics Demand Based on the Gravity Model. Manag. Rev. 2017, 29, 181-190. 
58. Sakai, T.; Kawamura, K.; Hyodo, T. Spatial reorganization of urban logistics system and its impacts: Case of Tokyo. J. Transp. Geogr. 2017, 60, 110-118. [CrossRef]

59. Ducret, R. Parcel deliveries and urban logistics: Changes and challenges in the courier express and parcel sector in Europe-The French case. Res. Transp. Bus. Manag. 2014, 11, 15-22. [CrossRef]

60. Cidell, J. Concentration and decentralization: The new geography of freight distribution in US metropolitan areas. J. Transp. Geogr. 2010, 18, 363-371. [CrossRef]

61. Sheffi, Y. Logistics Clusters: Delivering Value and Driving Growth; The MIT Press: Cambridge, UK, 2012.

62. Rivera, L.; Sheffi, Y.; Welsch, R. Logistics agglomeration in the US. Transp. Res. Part A 2014, 59, $222-238$. [CrossRef]

63. Diziain, D.; Ripert, C.; Dablanc, L. How can we Bring Logistics Back into Cities? The Case of Paris Metropolitan Area. Procedia Soc. Behav. Sci. 2012, 39, 267-281. [CrossRef]

64. Kumar, I.; Zhalnin, A.; Kim, A.; Beaulieu, L.J. Transportation and logistics cluster competitive advantages in the U.S. regions: A cross-sectional and spatio-temporal analysis. Res. Transp. Econ. 2017, 61, 25-36. [CrossRef]

65. Jin, X.; Long, Y.; Sun, W.; Lu, Y.; Yang, X.; Tang, J. Evaluating cities' vitality and identifying ghost cities in China with emerging geographical data. Cities 2017, 63, 98-109. [CrossRef]

66. Yang, W.; Chen, B.Y.; Cao, X.; Li, T.; Li, P. The spatial characteristics and influencing factors of modal accessibility gaps: A case study for Guangzhou, China. J. Transp. Geogr. 2017, 60, 21-32. [CrossRef]

67. Hu, H.; Ge, Y.; Hou, D. Using Web Crawler Technology for Geo-Events Analysis: A Case Study of the Huangyan Island Incident. Sustainability 2014, 6, 1896-1912. [CrossRef]

68. Chuang, H.-M.; Chang, C.-H.; Kao, T.-Y.; Cheng, C.-T.; Huang, Y.-Y.; Cheong, K.-P. Enabling maps/location searches on mobile devices: Constructing a POI database via focused crawling and information extraction. Int. J. Geogr. Inf. Sci. 2016, 30, 1405-1425. [CrossRef]

69. Comi, A.; Site, P.D.; Filippi, F.; Nuzzolo, A. Urban Freight Transport Demand Modelling: A State of the Art. Eur. Transp. Trasp. Eur. 2012, 51, 8.

70. Nathanail, E.; Adamos, G.; Gogas, M. A novel approach for assessing sustainable city logistics. Transp. Res. Procedia 2017, 25, 1036-1045. [CrossRef]

71. Gonzalez-Feliu, J.; Semet, F.; Routhier, J.L. Sustainable Urban Logistics: Concepts, Methods and Information Systems; Springer: Berlin/Heidelberg, Germany, 2014.

72. Li, Y.; Liu, Z.Q.; Zeng, X.; Jia, Y.S. Research on the Status and Distribution System of Urban Distribution in Guangzhou. Highw. Automot. Appl. 2015, 167, 82-87.

73. CNNIC. China Online Shopping Market Research Report; CNNIC: Beijing, China, 2016.

74. Sun, Y.; Wei, W.; Zheng, W.J. Research on Calculation Method of Logistics Park Construction Scale. Logist. Sci-Tech 2014, 37, 72-76.

75. Beijing Municipal Engineering Design and Research Institute. CJJ 37-2012 Code for Design of Urban Road Engineering; China Building Industry Press: Beijing, China, 2012.

76. Vieira, J.G.V.; Fransoo, J.C.; Carvalho, C.D. Freight distribution in megacities: Perspectives of shippers, logistics service providers and carriers. J. Transp. Geogr. 2015, 46, 46-54. [CrossRef]

77. Qi, Y.; Tao, L.; Jiao, J. Implementation methods and economic impacts of national node strategies. J. Geogr. Sci. 2017, 27, 348-364. [CrossRef]

78. Dablanc, L.; Ross, C. Atlanta: A mega logistics center in the Piedmont Atlantic Megaregion (PAM). J. Transp. Geogr. 2012, 24, 432-442. [CrossRef]

79. Mankiw, N.G. Macroeconomics, 9th ed.; Worth Publishers: New York, NY, USA, 2015.

80. Roger, P.R.; Prassas, E.S.; Mcshane, W.R. Traffic Engineering, 4th ed.; Pearson: New York, NY, USA, 2010.

81. Arvidsson, N. The milk run revisited: A load factor paradox with economic and environmental implications for urban freight transport. Transp. Res. Part A 2013, 51, 56-62. [CrossRef]

82. Buren, N.V.; Demmers, M.; Heijden, R.V.D.; Witlox, F. Towards a Circular Economy: The Role of Dutch Logistics Industries and Governments. Sustainability 2016, 8, 647. [CrossRef]

83. Perboli, G.; Musso, S.; Rosano, M.; Tadei, R.; Godel, M. Synchro-Modality and Slow Steaming: New Business Perspectives in Freight Transportation. Sustainability 2017, 9, 1843. [CrossRef]

84. Pazour, J.A.; Meller, R.D.; Pohl, L.M. A model to design a national high-speed rail network for freight distribution. Transp. Res. Part A 2010, 44, 119-135. [CrossRef] 
85. Behiri, W.; Belmokhtar-Berraf, S.; Chu, C. Urban freight transport using passenger rail network: Scientific issues and quantitative analysis. Transp. Res. Part E 2018, 115, 227-245. [CrossRef]

86. Zhou, G.; Ou, X.; Zhang, X. Development of electric vehicles use in China: A study from the perspective of life-cycle energy consumption and greenhouse gas emissions. Energy Policy 2013, 59, 875-884. [CrossRef]

87. Trentini, A.; Malhene, N. Flow Management of Passengers and Goods Coexisting in the Urban Environment: Conceptual and Operational Points of View. Procedia Soc. Behav. Sci. 2012, 39, 807-817. [CrossRef]

88. Triantafyllou, M.K.; Cherrett, T.J.; Browne, M. Urban Freight Consolidation Centers Case Study in the UK Retail Sector. Transp. Res. Rec. 2012, 2411, 34-44. [CrossRef]

89. Gössling, S.; Schröder, M.; Späth, P.; Freytag, T. Urban Space Distribution and Sustainable Transport. Transp. Rev. 2016, 36, 1-21. [CrossRef]

(C) 2018 by the authors. Licensee MDPI, Basel, Switzerland. This article is an open access article distributed under the terms and conditions of the Creative Commons Attribution (CC BY) license (http:/ / creativecommons.org/licenses/by/4.0/). 